\title{
From Change to Stability:
}

\section{An Evaluation of Change and Performance at Canada's Office of the Auditor General}

\author{
By
}

Jordan Taft

A thesis submitted to the Faculty of Graduate and Postdoctoral Affairs in partial fulfillment of the requirements for the degree of

\author{
Master of Arts \\ in \\ Political Science \\ Carleton University \\ Ottawa, Ontario \\ (C) 2014 \\ Jordan Taft
}




\begin{abstract}
$\underline{\text { Abstract }}$
Through its audits and recommendations, Canada's Office of the Auditor General (OAG) has promoted financial probity and good governance for over a century. While the OAG's recommendations may possess an inherent value, their full value is realized only through their implementation by government. By investigating OAG recommendation implementation rates, and the OAG's interaction with Parliament, this thesis evaluates recent performance at the OAG.

Two research questions are considered: first, has OAG performance changed since 1993; and second, have its interactions with Parliament and government changed over the same period? Have changes in government, or in the interaction between the OAG and Parliament, affected the OAG's work or Parliament's investigation of its audits?

The OAG's performance is considered from various angles, including an assessment of OAG data to quantify recommendation implementation rates and interactions with Parliament over time. Numerous stakeholder interviews are also utilized to provide a well-rounded qualitative perspective on these questions.
\end{abstract}




\section{$\underline{\text { Acknowledgements }}$}

I owe a great debt of thanks to the many people upon whom I have relied throughout this project. Without your help, advice, insights, feedback, and support I would not have been able to see this thesis through to the end. I can't name you all, but a few stand out:

To those currently and formerly employed by the Office of the Auditor General, and the Government of Canada, who helped me along the way: a sincere thank you for sharing your time and perspectives. My data set and analysis could hardly have been completed without your assistance.

Thanks to Dr. Jonathan Malloy and my professors at Carleton University. Your feedback, support, advice, and guidance have helped my through this project, and the Master's program in Political Science. A special thanks to Dr. Rand Dyck, who I consider a valued friend.

This thesis would not have made it far without the support of my parents. Sounding board, encouragement, and hours of editing - thanks for all the roles you've played over the past two years.

Finally, Shaheen. Through thick and thin, you've been by my side. For all you've done, I couldn't be more grateful. 


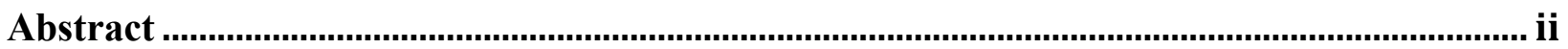

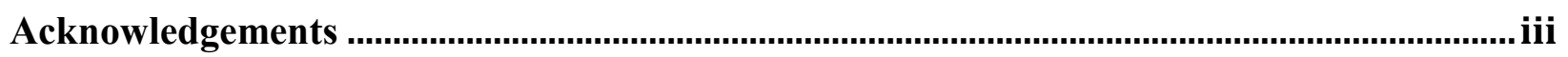

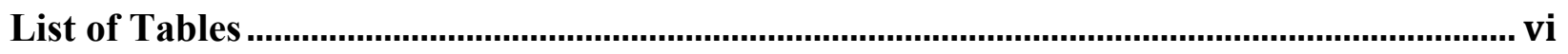

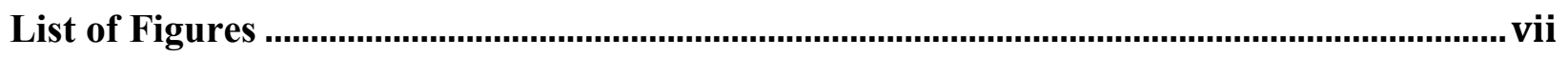

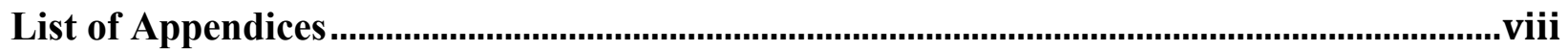

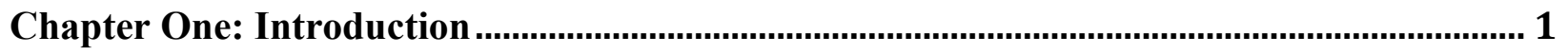

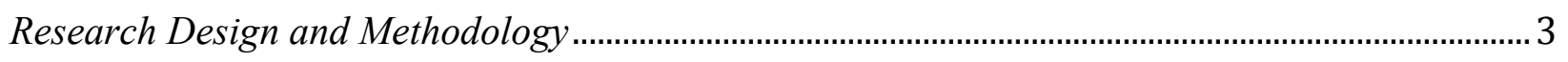

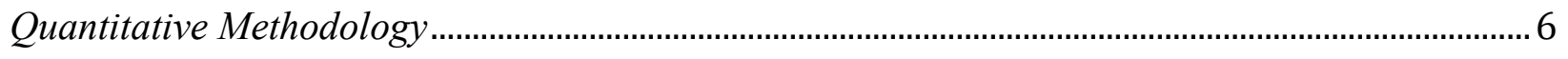

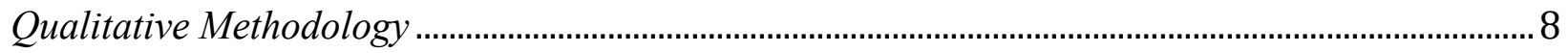

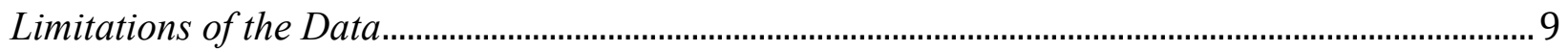

Chapter Two: Evolution and Change at the OAG and PAC ...............................................11

The OAG's Historical Performance: Controversial and Dynamic Change ................................... 12

Interaction Between the $O A G$ and Parliament: The Standing Committee on Public Accounts ... 22

Chapter Three: Accountability, Auditing, and Financial Administration ............................ 27

Parliamentary Concepts: The Fundamental Role of Responsible Government ............................. 28

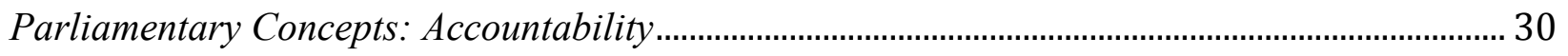

Parliamentary Concepts: How Does Accountability Relate to Responsible Government? ........... 34

Parliamentary Concepts: Financial Administration ....................................................................... 36

Questions of Performance: Auditing, Accountability, and Financial Administration................... 41

Chapter Four: OAG Performance Over Time...............................................................................48

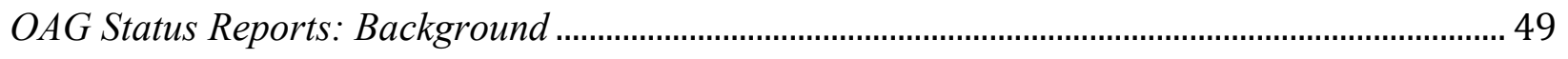

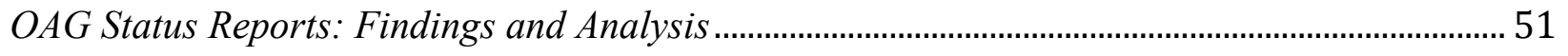

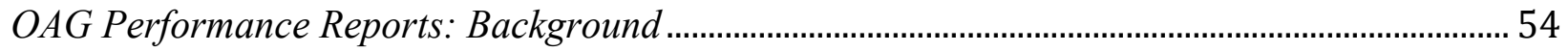

OAG Performance Reports: Findings and Analysis.................................................................... 56

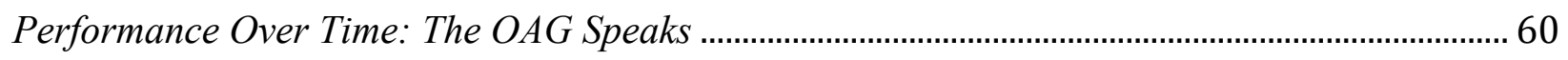

Chapter Five: Interactions Between the OAG and Parliament ............................................. 72

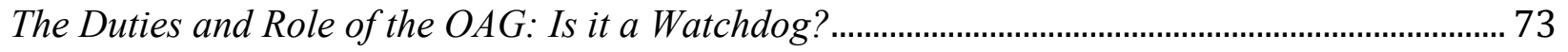

OAG-Parliamentary Interaction by the Numbers .............................................................................. 82

Institutional Interactions: The Inside Perspective .............................................................................. 87 


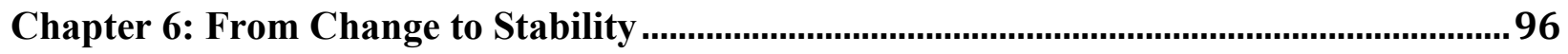

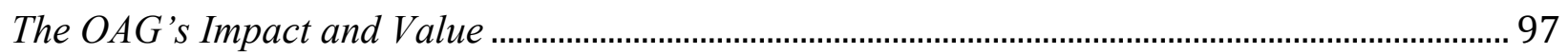

The Importance of Parliament …………………………............................................................... 99

Institutional Strengths and Limits ..............................................................................................101

The More Things Change, the More They Stay the Same …………………………......................103

Appendix A: Office of the Auditor General Interview Questionnaire ................................... 105

Appendix B: Standing Committee on Public Accounts Interview Questionnaire .............. 107

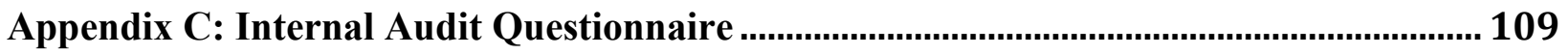

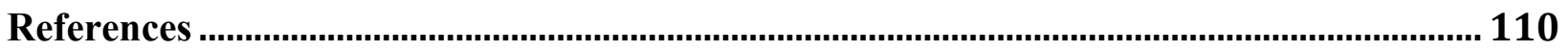




\section{$\underline{\text { List of Tables }}$}

Table One: OAG Status Report Analysis of Recommendation Implementation, 2002-2013

Table Two: Performance Audit Recommendation Implementation Rates, 1996-2013 


\section{$\underline{\text { List of Figures }}$}

Figure One: OAG-Parliamentary Interaction

Figure Two: Percent of OAG Performance Audits Reviewed By Parliament 


\section{$\underline{\text { List of Appendices }}$}

Appendix A: Office of the Auditor General Interview Questionnaire

Appendix B: Standing Committee on Public Accounts Interview Questionnaire

Appendix C: Internal Audit Questionnaire 


\section{Chapter One: Introduction}

Since 1878, the Office of the Auditor General (OAG) has scrutinized the accounts of Canada's federal government. At its most basic, the OAG's role has been to audit government spending, ensuring that public funds have been spent as intended. While this role has changed over time, its fundamental aim remains the same. Yet the OAG has not remained static.

Numerous legislative changes have meant the OAG of today bears little resemblance to the OAG of 1878. Many of its historic responsibilities have been delegated to departmental or internal auditors, and various new obligations have arisen in their place. The OAG has grown from its humble beginnings into an integral component and key institution of Canada's accountability framework.

While legislation has been an historical harbinger of change for the OAG, it has largely subsided since the 1977 Auditor General Act. What other influences might have affected - or be affecting - the OAG? Is it possible the operations of the OAG have changed due to their own accord, or through non-statutory interactions with political actors? What might such influences mean for the value added by the OAG to Parliamentary accountability processes? After all, auditors have come under increasing scrutiny vis-à-vis their own performance, and some scholars have questioned the proliferation and value of auditing (Power 1997, Lonsdale 2011).

Given such criticism, and a lack of aggregate data on the OAG's performance over time, this thesis analyses a compilation of both quantitative and qualitative data to investigate whether and how the OAG's performance has changed over the last two decades. Has it improved, declined, or stayed the same? The questions, and therefore the thesis, are exploratory in nature. 
As the OAG can point to problems, but not fix them, its recommendations and their implementation are studied in detail. Recommendation implementation is only one indicator of the OAG's performance, but it has important implications for improvement to the accountability process in particular, and public administration in general. To this end, Status and Performance Reports of the OAG, spanning the period from 1994-2013, were analyzed to detect and assess any changes in the issuing, tracking, and implementation of recommendations. This quantitative analysis only partially shows whether change has taken place in the past two decades. To supplement this perspective, interviews were conducted with various government officials and academics involved either in the OAG's work or the broader accountability and budgetary processes of government. Together, these quantitative and qualitative data sets give a more comprehensive picture of the OAG's performance throughout the past two decades.

Based on the primary data and secondary sources studied, an argument will be made in this thesis that the OAG has entered a phase of stable continuity. Over the time period examined, it will be shown how a gradual process of endogenous change has slowly taken place. However, regarding the key metrics assessed in this paper-implementation of OAG recommendations and interactions with government - the trend will be shown to be one of consistency. Likewise, a case will be made that the OAG's recent relationship with Parliament echoes trends dating back to the late $19^{\text {th }}$ century, essentially remaining consistent over time. The research undertaken for this thesis will illustrate that the OAG has developed into a mature, self-aware political institution. Keenly aware of the legislation that imposes boundaries and limits the scope of its operations, the OAG has learned to manage its relationship with both Parliament and the accountability structures of the federal government. This thesis will show how this phase of stability in the OAG, not free of the occasional change or controversy but present for at least the 
last two decades, is an indication of an established, mature audit function serving Canada's federal government.

\section{Research Design and Methodology}

The research design for this project consists of two research questions which are explored and assessed with quantitative and qualitative measures. It is important to note that this research is exploratory in nature. Due to the nature of the questions asked, the availability of data, and the nature of interviewing, a definitive answer to the questions cannot be given. Despite this lack of certainty, enough detail is present in the data collected to enable the formulation of strong and supportable conclusions and analysis.

The first question examined is the OAG's performance vis-à-vis government implementation of its recommendations. Although ultimately beyond the OAG's control, recommendation implementation is an important indicator of whether problems identified by the OAG are being addressed by the government. A question currently being asked at the $\mathrm{OAG}$ is 'what value are we adding to the government and public service?' Expanded on in Chapter Four, this question parallels the examination of recommendation implementation in an important way, for what value do recommendations have if they are not acted upon? The question then becomes, what do implementation rates look like, and have they changed over time? In broad terms, the first question can be thought of as follows: in the last two decades, has the OAG's performance in carrying out its accountability function changed over time, and if so, how?

The key concept to be measured and operationalized is 'performance.' What exactly does performance entail? The concept of 'performance' is multifaceted. The OAG itself uses several criteria to measure and assess its own performance, including implementation of 
recommendations, Parliamentary review and approval of reports, conducting its business on time and on budget, and employee satisfaction. To operationalize the concept of 'performance,' this project will focus on the first of these criteria: recommendation implementation. In considering the performance of the OAG vis-à-vis changes over time, recommendation implementation rates are the main benchmark of assessment. This is admittedly only one aspect of 'performance' as construed by the OAG, and only one aspect of the concept of 'performance' in general. By using one of the OAG's own criteria this project undertakes an in-depth temporal analysis of a specific performance measure that closely mirrors those done by the OAG itself.

Any consideration of 'performance' is difficult to achieve, particularly in assessing changes over time. By focusing on a narrow indicator, which the OAG itself uses, this project has been able to investigate changes in performance, albeit in a limited manner. The OAG's other criteria of performance - budgetary, punctuality, and employee satisfaction - are not addressed. While valid indicators of performance, these measures do not directly relate to the research questions from a political science perspective.

The second major question examined asks whether the relationship between the OAG, Parliament, and the federal government has changed over time. The quantitative and qualitative data collection methods employed for this thesis provide insight into several pertinent areas. Implementation rates are considered in relation to government tenure and change. If performance changes are found, and tied to a particular year, does that year match the introduction of a new government? Did the changes occur early or late in the tenure of a government? As well, interaction between the OAG and Parliament - characterized as the OAG's participation in Parliamentary committee hearings and briefings, and Parliamentary review of OAG audits - is assessed. This allows insight into how regularly the OAG and Parliament interact, as, after all, 
the OAG must rely on such contact and Parliamentary attention for its work to realize its full potential. The interview process also highlights less obvious but important changes in the relationship between these institutions.

The second question is essentially an assessment of Parliamentary involvement and influence in the OAG's work - the interactions between these two institutions. Since the framework for this project is situated in financial administration and accountability as they relate to Canada's Parliament, it is only fitting to consider this interaction. While government departments implement the OAG's recommendations, Parliament and the Standing Committee on Public Accounts (PAC) play an important role in this process, as discussed in Chapters Two and Three. The OAG itself measures Parliament's involvement in its work, and so this question benefits from mirroring the OAG's own self-assessment. Ultimately, an assessment of performance from the perspective of parliamentary involvement helps to assess the OAG's capacity to influence and be influenced.

This thesis focuses on a twenty-year period for several reasons. First, the OAG's reporting formats have changed over time, and since the early $1990 \mathrm{~s}$, and later, the 2000s, its Performance and Status Reports have respectively matured. Second, the span of time covers almost the entire Chrétien majority government, the minority years from 2004 to 2011, and the beginning of the Harper majority; this allows for an examination of the OAG's performance under different political contexts. Third, the OAG and its mandate went through a tumultuous period during the 1960s and 1970s, and the years under examination represent a relatively quiet and stable period; this allows for a more accurate and realistic analysis of the OAG's performance and relationship with Parliament. 


\section{Quantitative Methodology}

The project's quantitative research measure focuses on an assessment of OAG audit recommendations. The OAG lists implementation of previous recommendations as a major indication of its performance (OAG Performance Report 2001/02, 7), and a multi-year assessment of these implementation rates provides an important perspective on whether the performance of the OAG has changed. For the purposes of this study, the implementation rates were tracked and compiled in a database, and compared over time. A secondary question related to this data collection and analysis was whether and how the OAG's tracking of recommendation implementation has changed, including the OAG's methods and number of recommendations tracked each year

The OAG's Status Reports and Performance Reports constitute the sample for this question. Status Reports (SRs), which were introduced in 2002, explicitly track and re-audit the implementations of previous recommendations and reports. Prior to the introduction of SRs, the OAG relied primarily on departmental self-reporting and loose follow-up from OAG staff to determine recommendation implementation. SRs represented a desire to gain a more concrete and verifiable understanding of the status of previous recommendations; they were also an attempt to separate follow-up audits from new audits (OAG Status Report 2002, 1). Only a limited number of OAG recommendations are covered in these reports, and the extent to which the sample represented by SRs correlates to the broader population of OAG recommendations and their implementation rate is unknown. As far as it is known at this time, the OAG has taken no steps to establish such a correlation.

Performance Reports (PRs) have been issued by the OAG since the mid-1990s. These reports are a general indicator and self-assessment of the OAG's performance. They cover 
various topics, including employee satisfaction, budgetary and deadline goals, survey results, and other indicators of performance. They also include aggregated data on recommendation implementation and the OAG's interactions with Parliament. While a majority of the data regarding recommendation implementation is not verified and is mostly based on departmental self-reporting, the sample represented by PRs is the largest, if also the most unreliable. They have been examined with this caveat in mind.

Annual Reports generally outline and address new audits performed by the OAG. To the extent that these reports address recommendation implementation, however, they have been studied in brief. This is particularly relevant for the pre-SR period, at which time recommendation follow-up was included in Annual Reports. The relevant data available in Annual Reports from the 1990s is of uncertain quality and disparate formats, however, and for the purposes of this project were largely eschewed in favour of Status and Performance Reports.

Results from the reports have been compiled in a database, which forms the basic instrument for tracking recommendation implementation. Various measures are included in the database in an effort to assess change from as broad a perspective as possible. These include, for example, the number of recommendations issued each year, the type of progress made on recommendations, and the timeline for progress (what year a recommendation was made versus when its progress is assessed).

The measurement of recommendation implementation itself has already been done by the OAG; to actually measure implementation is far beyond the scope of this project. Rather, only implementation rates and any change therein have been measured - in the process essentially aggregating OAG data and examining it from a temporal perspective to assess whether change has occurred. 


\section{Qualitative Methodology}

The qualitative research centers on several elite interviews with relevant actors. These interviews have served to fill in the blanks and answer questions not addressed in the OAG's written reports. They have also provided a broader, more nuanced perspective on the question of performance over time, as the numbers behind recommendation implementation are only one aspect of the performance question. The interviews have provided insight into the inner workings of the OAG and endogenous change at the office, the effects Parliament and the government have had on the OAG, and the OAG's broader relationship with, and situation in, parliamentary accountability structures and financial administration.

The qualitative sample consists of ten interviews. The interviewees included employees of the OAG and auditors general; government managers and researchers, including public servants involved in departmental internal audit services; parliamentarians; and academics. The interviews were either recorded, or written down afterwards based on extensive note taking.

Three different sets of questions were developed. Each set was designed for different interviewees - one set for OAG employees, one set for parliamentarians and members of the Standing Committee on Public Accounts Committee (PAC), and a set for public servants involved in internal audit functions. Within each set, standard questions were asked of each interviewee. The questions addressed underlying issues surrounding accountability, the OAG, financial administration, and changes in performance over time. This method is the most comprehensive and is best suited to create a wide range of responses and capture varying qualitative perspectives. In the course of each interview, the conversation sometimes led to unique follow-up questions. While this reduced the uniformity of the questions, it enabled a 
better understanding of various issues that arose in each interview. Each questionnaire can be found in the Appendices.

Although each type of questionnaire was tailored to its intended subject, general themes overlapped the questionnaire sets. The interviews began with a set of introductory questions aimed at the role and duties of the OAG, including whether the OAG is a 'financial watchdog.' The second major question theme was the OAG's performance over time; numerous questions were formulated to address this area, and related to OAG procedures and approaches, recommendation implementation and follow up, and the influence of individual auditors general. The third theme was the OAG's relation to Parliament, government, and the PAC. Questions falling under this theme attempted to determine the tenor and scope of the relationships between these bodies, whether any changes have occurred therein, and where applicable, the causes of such change. Each interview ended with an open question asking the participants for any further input, or other issues they wished to raise.

\section{Limitations of the Data}

It is important to stress the limits of the quantitative and qualitative data sets. This thesis is exploratory by nature, and does not pretend to offer a final or definitive view on the question of recommendation implementation, or the OAG's relationship with Parliament and the government. The quantitative data set is incomplete, and most likely will always be; the OAG simply does not have the resources to follow-up on every audit and the implementation of its recommendations. To be certain that implementation has occurred, re-audits must be carried out. The level of work involved is high, and as a result is limited. While it is thus possible to outline 
implementation rates for a small number of recommendations, anything short of a massive undertaking will fail to assess a comprehensive rate for all OAG recommendations.

Likewise, any interview process cannot hope to be completely comprehensive. The ten interviews conducted represent but a snapshot of perspectives on the OAG and Parliament. Especially with such a small sample size, its generalization to the broader public service community cannot be made. Yet by strategically choosing relevant actors with significant experience, each of whom occupied (or occupies) a key place in the accountability process, the limits of this process have been tempered to an extent by the breadth and nuance of opinion offered by the respondents.

This thesis consists of six chapters. Following the Introduction, Chapter Two is an exploration of the OAG's role as an accountability-enhancing institution, both from an historical and contemporary perspective, and its relation to Parliament and the Standing Committee on Public Accounts. In Chapter Three, pertinent theoretical conceptions related to the OAG, including responsible government, accountability, financial administration, and auditing are addressed. A discussion of these issues is necessary to understand the OAG's role and performance in Canada's parliamentary system. Chapter Four is an analysis of the OAG's performance over time based on the aggregated data from OAG reports and the interviews. By using the same approach as Chapter Four, Chapter Five explores the OAG's relationship with Parliament. The final chapter is a reflection on the data gathered, the OAG's place in Canada's parliamentary system, and the institution's current position relative to its history. 


\section{Chapter Two: Evolution and Change at the OAG and PAC}

A grasp of the OAG's history and evolution is required to assess and understand any changes to its recent performance and interactions with Parliament. In order to determine whether the OAG has changed, it is necessary to understand how it once was. Only by examining its past performance, statutory obligations, and interactions with Parliament can an accurate assessment of the OAG's recent activity be carried out. While a comparison could be based strictly on the reporting period studied in this thesis, a broad and historical investigation provides a more fulsome insight into the office's past and current operations. What emerges is a picture of a mature institution, at times characterized by controversy and struggle with the government, which has slowly come into its own through a gradual process of evolution and change. A number of questions are of key importance: how was the office created, and how has it evolved; what were its original functions, and its relationship with government; and, what events precipitated change at the office, and were they endogenous or exogenous in origin?

These questions - and their answers - shape a picture of an office that has changed significantly over the past century. The OAG has had a dynamic, rather than static, history. It has changed in response to political debate, and at times has shaped that debate. It has been the government's ally and antagonist. By investigating and explaining past changes to the OAG, as well as to the Standing Committee on Public Accounts (PAC), this chapter sets the contextual groundwork for an investigation of the OAG's current performance and its interactions with Parliament. 
The OAG's Historical Performance: Controversial and Dynamic Change

What was the OAG intended to do, and how might its history have shaped its current performance? As Canada's oldest agent of Parliament, the OAG has had a long and colorful history. From its early beginnings in the $19^{\text {th }}$ century, through to major reform in the 1930 s and 1970s, the office has experienced a steady stream of criticism and change. It has evolved into an institution esteemed by the public, and not infrequently reviled by the government. While this section does not provide an exhaustive account of the OAG's varied history, it will focus on the key points in its evolution.

First established in 1878 with the passage of the Bill for the Better Auditing of Public Accounts, the creation of Canada's Auditor General received widespread support from MPs (Sinclair 1979, 17). The bill established the Auditor General as an independent monitor (one who could not be easily fired) with limited staffing powers, and framed the position as one designed to enhance the power of Parliament (ibid.). The first Auditor General, John Lorn McDougall, quickly proved to be a fastidious and unsympathetic critic of government spending; criticism from MPs and the bureaucracy was not far behind. A debate between Z.A. Lash, Deputy Minister of Justice, and Mr. McDougall in 1879 - less than a year after the position was created - marked the beginning of an often acrimonious relationship between the Auditor General and Parliament (ibid., 20).

Prior to this bill, the legislative auditor was also Deputy Minister of Finance, who on one hand authorized spending as a member of the government, and on the other criticized it as an auditor (Franks 1987, 238). Given the conflicting nature of such a position, it is unsurprising that such a situation was remedied. However, the newly created Auditor General had a similarly awkward duty: the Bill for the Better Auditing of Public Accounts required that the Auditor 
General not only examine past spending, but also give permission for the "disbursement of government funds" (Franks 1987, 238). The Auditor General thus had control at both ends of the financial cycle, deciding whether or not to allow spending, and then criticizing the spending that did happen. In Sinclair's words, the Auditor General "was empowered to pass judgment on expenditures both before and after they had been incurred" $(1979,19)$.

What exactly was the OAG initially set up to do, and how was it to relate to government? Simply put, the goal (or mandate) of the OAG was to provide independent accounting of the government's expenditures (ibid., 17). Appointed as an officer of Parliament, in contradistinction to the government, the OAG was designed to enhance Parliament's control of the financial process, in accordance with the principle of legislative supremacy (Balls 1978, 587). To this end, the OAG was designed to be independent of the executive, but answerable to Parliament; the officer could only be removed by a combined action of the House of Commons and the Senate (ibid., 588). The OAG was given clear control over certain parts of the financial process, from the issuing of treasury credit to the auditing of vouchers and cheques. The goal of this process, as Balls notes, "was to establish legislative control without diminishing executive responsibility" (ibid.). The OAG was intended to aid parliamentarians by providing a substantive check on the financial process - a role that could not always be easily fulfilled by MPs.

Despite this clear mandate, specific limitations were placed on the OAG. Anticipating the possibility of a reticent or parsimonious auditor general, allowance was made for the government to issue credit in certain circumstances (ibid., 589). These restraints served to limit the OAG's power, thereby preserving Parliamentary and government prerogatives in the disbursement of public funds. As a result, the OAG was designed for a distinct purpose, with clear limitations to curb its power. 
How was the OAG to go about accessing the information it required for its duties? As Balls recounts, sweeping powers were given to the $\mathrm{OAG}$ in this regard: free access to departmental accounts and materials relating to them; the power to examine a person under oath or affirmation; application to the judiciary for subpoenas; and commissioning persons to gather information and report to the OAG. Penalties were also instituted for those failing to obey the OAG's requests (Balls 1978, 588). Despite these sweeping powers, however, access to information was to become a recurring problem for McDougall and his successors.

Notwithstanding a supposedly clear mandate, limitations, and powers, McDougall did not experience a welcome reception from government. Probably because the man was fastidious and close-fisted to an extreme (Sinclair 1979, 17-29), he quickly came into conflict with the government:

As Parliament and the government soon discovered, it was one thing to say that the Auditor General should be independent and that he should possess extensive powers; it was altogether different to live with the consequences of the new legislation, or to define the precise scope of those powers (ibid., 18).

Less than a year passed before McDougall was challenged on his mandate, in 1879. Z.A. Lash, the Deputy Minister of Justice, disagreed with the Auditor General regarding his criticism of the government's right to authorize spending by Order in Council (Balls 1978, 593). Very quickly, an argument emerged over the proper scope of the OAG, and what it could and could not do. This arose in part due to the OAG's initial power regarding both the disbursement and audit of public funds; McDougall was attempting to exercise control over the former aspect, while Lash thought he should be confined to the latter. It soon became practice for the government to ignore or overrule the OAG: McDougall was overruled more than 100 times during his career (Sinclair 1979, 22). 
Clearly the OAG and government did not see eye-to-eye on the proper scope and duties of the office. One result was an ongoing struggle over access to information, as McDougall found that he was consistently denied information "on the grounds that it was unobtainable, confidential or outside his mandate" (Sinclair 1979, 24). To what extent such excuses were valid or concocted is uncertain; their use, however, appears to have been in stark contrast to the sweeping powers given to the $\mathrm{OAG}$ for the purposes of gathering information. Of particular importance is the connection between access to information and the mandate of the OAG: an unclear mandate fomented not only conflict, but also allowed for government obfuscation when presented with requests for certain information.

Despite the early conflicts between the government and OAG, McDougall did lay the groundwork that was to serve as a model for successive Auditors General. A precedent for the OAG's operations was established; while questions remained about the proper scope of the OAG's activities, consensus nonetheless existed on other aspects of its mandate. The auditing of government expenditures was established, and numerous examples of pecuniary mismanagement were uncovered and rectified. Despite the arguments and confrontations, Parliament had become used to the presence of the OAG during McDougall's lengthy tenure.

The conflicts between the OAG and government, however, most likely served to mar the relationship between the two. Sinclair speculates that the selection of McDougall's reserved and non-confrontational successor, John Fraser, was a direct result of the government's desire to avoid another outspoken critic of its activities (Sinclair 1979, 35). Balls also notes that McDougall's successors did not engage in the "violent disagreements" that had characterized their predecessor's time in office (Balls 1978, 596). The hallmarks of McDougall's careerdisputes over the OAG's mandate and access to information, and its adversarial relationship with 
an oft-hostile government - produced a mixed record. Challenges existed, but whether they were approached in the right way is a matter of debate.

The period following McDougall's retirement, from 1905-1931, was one of relative quiet for the OAG. Its first major revision fell under the tenure of Prime Minister R.B. Bennett. Hoping to ascertain the state of the nation's finances upon coming to office in 1930, Bennett found them in such disarray as to render them incomprehensible (Franks 1987, 239). Due to a credit-based system designed to avoid the Auditor General's pecuniary permissions, there was little in the way of coordinated control or approval over departmental spending (Sinclair 1979, 43). Passed in 1931, the Consolidated Revenue and Audit Act (CRAA Act) established, among other things, the Auditor General as a formally independent Officer of Parliament. The CRAA Act also saw the almost total removal of the OAG's "pre-audit" functions, which were largely taken over by the newly created Comptroller General (Balls 1978, 599), thereby eliminating the OAG's control over the disbursement of public funds. The government's ability to manage its finances was changed, and for the first time a truly independent federal auditor was in existence (Franks 1987, 239).

The OAG continued to produce annual reports, although little attention was paid to them and the office languished in relative obscurity (ibid., 239). The choice of R. Watson Sellar as Auditor General in 1940, however, marked a period of increased influence and legitimacy for the OAG (Sinclair 1979, 46-50). This increased attention was augmented in 1958, when Prime Minister Diefenbaker held true to an election promise and instituted an opposition MP as Chair of the PAC. As Franks notes, this created a strong incentive for scrutiny of government spending (1987, 239). During this period the 1951 Financial Administration Act modestly expanded the 
powers of the OAG, but in reality set the stage for further debate and legislative change (Sinclair $1979,55)$.

The larger controversy began in the 1960s under Maxwell Henderson's tenure, following Sellar's retirement in 1959. Henderson, Auditor General from 1960-1973 and the first Chartered Accountant to hold the position (Franks 1987, 239), presided over a period of growing disagreement with the government in regard to the role of the OAG. Questions about the staffing of the office, its relationship with the government, and the proper scope of the OAG's activities and authority all combined, and led to a period of fundamental change and restructuring for the office. While the controversy perhaps had its roots in Sellar's reporting of 'non-productive payments,' in which Sellar reported on instances of what he believed to be poorly spent money, it was under Henderson, and eventually James Macdonnell, that the issues reached their climax and denouement.

Henderson continued Sellar's practice of reporting on non-productive payments, and engaged in a debate with the government over the adequate staffing of the OAG (Sinclair 1979, 77). Arguing that he was being denied an adequately classified staff, Henderson felt the ability of the OAG to do its job was being impeded by the government (Wilson Report 1975, 2). Did the OAG have the proper resources to fulfill its mandate? The answer was one of perspective, and depended largely on whether one was a member of the government or employed in the OAG.

More important than the staffing issue was the question of the proper scope and mandate of the OAG. This emerged directly out of Henderson's reporting on non-productive payments. The government argued that such reporting was improper, and that by carrying on such practices the OAG was unduly commenting on policy matters - an area clearly outside of its jurisdiction 
and mandate (Balls 1978, 606). This issue of propriety outlasted Henderson, and was to be taken up in full by his successor, James Macdonnell.

Upon assuming office in 1973, Macdonnell expressed "an immediate interest in the question of his role and responsibilities" (Wilson Report 1975, 3). Concerns regarding the proper scope of the OAG were unresolved; the media and public loved the reporting of non-productive payments, while the government felt it was improper and threatened the validity of the OAG itself (Sinclair 1979, 70). At issue was the question of what exactly the OAG should be mandated to do: should its audits strictly focus on the legality of government spending, ensuring such activities conformed to the desire and instruction of Parliament? Or should the OAG also be allowed to comment on the economy, effectiveness, and efficiency of government expenditures? The OAG's mandate, set out in the Financial Administration Act, was vague on this point. Of particular issue was a clause allowing the OAG to report on "any other case that [he] considers should be brought to the notice of the House of Commons" (Wilson Report 1975, 20). The ambiguity of this clause, and the ensuing controversy over what the OAG should and should not report on, resulted in an important public debate on the proper scope of the OAG's mandate.

Macdonnell's solution was to launch an “Independent Review Committee" designed to both investigate the problems surrounding the OAG and propose solutions. Headed by Mr. J.R.M. Wilson, FCA, the Committee published in 1975 what was colloquially termed the 'Wilson Report.' This report reviewed the responsibilities of the OAG, including its proper scope, reporting practices, independence, and the relationship that should be maintained between the OAG and the government. The report offered various recommendations, including a need for new legislation, continued independence, and strengthened jurisdiction over staffing procedures. The report included a recommendation regarding the scope of the OAG's mandate, proposing 
that it should be allowed to conduct value-for-money (VFM) audits (Balls 1978, 608).

Furthermore, it was noted that the OAG's access to information should be defined "not in relation to the Government's accounts, but in relation to the responsibilities assigned to him" (Wilson Report 1975, 101). The Wilson Report proved to significantly inform the debate around the OAG, and its recommendations definitively shaped the impending Auditor General Act of 1977.

Of prime importance was the VFM concept, which consisted of three ideas: economy, efficiency, and effectiveness (Franks 1987, 240). According to Sinclair, economy is "acquiring resources of an appropriate quality for the minimum cost," efficiency "refers to the manner in which human and material resources are used to achieve desired results," and effectiveness "is the extent to which a program achieves its objectives" $(1979,116)$. While the concepts of economy and efficiency were relatively uncontroversial, the Wilson Report's proposal of effectiveness as part of the OAG's powers was hotly debated (ibid., 117). A major concern was the extent to which the OAG should comment on policy, of which judging effectiveness was considered part and parcel. Such debate, the government maintained, was the prerogative of Parliament (ibid., 119). Alongside this concern was the fear that the OAG could become politicized, in the process losing its independence (ibid., 120). Minor concessions were made, and despite this controversy, the VFM concept was to become an integral part of the Auditor General Act.

Almost one hundred years after John Lorn McDougall became the first Auditor General of Canada, the OAG was given a modern and definitive piece of legislation. Passed in 1977, the Auditor General Act was the culmination of over a decade's worth of legislative proposals. Previous legislative efforts were made to reform the OAG in 1969, 1970, and 1973, but each met 
with defeat for various reasons. The 1977 Act directly addressed many of the concerns raised by Henderson, Macdonnell, and the Wilson Report. Of major consequence, the scope of the OAG was clarified in an attempt to lead the OAG away from an emphasis on non-productive payments, and towards the beginning of the era of the VFM audit (Savoie 1990, 34). The end result, as Savoie notes, was an OAG whose "mandate and scope have been substantially strengthened" (ibid., 33).

With the passage of the Act a degree of clarity had been achieved. The question of scope was largely resolved, and having its own legislation increased the legitimacy of the OAG. As a result, the controversy surrounding the office, including what had become an acrimonious relationship between the OAG and the government, was largely laid to rest. Sections 15 to 18 of the new act included a lengthy section on the staffing of the $\mathrm{OAG}$, and to an extent strengthened access to information (Sinclair 1979, 122). Multiple controversies, some going back almost twenty years to Sellar's era, were resolved.

What are the modern functions of the OAG? Sections 5-7 of the Auditor General Act lay out the "powers and duties" of the OAG. Section 5 establishes that the OAG "is the auditor of the accounts of Canada." Section 7.1 stipulates that the OAG report annually to the House of Commons. This is an important distinction in regard to accountability, for if the OAG reported to Cabinet there would be no means for Parliamentary oversight of government spending. Section 7.2 (a-f) enumerates cases that the OAG should call to the attention of the House of Commons: while subsections (a) through (c) deal with traditional financial audit concerns, subsections (d) and (e) give the OAG the power to conduct performance audits. Concerned with the questions of economy, efficiency, and effectiveness, performance audits were at the heart of the debates over 
VFM and the scope of the OAG's mandate during Henderson's and Macdonell's careers; these audits are explored more fully in Chapter Three.

Despite the passage of the Auditor General Act, certain problems still remained. Kenneth Dye, Auditor General from 1981 to 1991, has written about the problems he experienced with access to information. Arguing that he had the right to access certain information, Dye has claimed that political concerns played a role in the government's refusal to provide information on issues pertaining to crown corporations (Dye 2003, 233). Criticism was also shortly forthcoming regarding the OAG's new VFM role (Sutherland 1980), and Section 7.2 of the Auditor General Act still stipulated that "the Auditor General under subsection (1) shall call attention to anything that he considers to be of significance and of a nature that should be brought to the attention of the House of Commons." This clause, mentioned as potentially troublesome by the Wilson Report due to its ambiguity, nonetheless was still included in the new Act. The debate over the proper role and impact of agents of Parliament, including the OAG, has thus continued (for example, see Savoie 1990 and Stilborn 2010). Regardless of such debates which are, in reality, most likely the indication of a healthy democracy - the 1970s saw for the most part the successful resolution of the controversies and problems facing the OAG.

Since the passage of the Auditor General Act, the duties of the OAG have remained largely unchanged. The office has its own Act, its mandate has been clarified, and it is for the most part free from controversy. The job of the modern OAG bears little resemblance to the duties performed by McDougall in the $19^{\text {th }}$ century. Yet these changes did not emerge overnight. It was only through a series of controversies, debates, commissions, reports, and legislative changes that the OAG has reached its modern form, having faced numerous struggles along the way. 
Interaction Between the $O A G$ and Parliament: The Standing Committee on Public Accounts

In order to fully explore the second research question of this thesis - the OAG's interaction with Parliament - the Standing Committee on Public Accounts (PAC) must be considered. With a mandate charging it to "review and report on the Public Accounts of Canada and all reports of the Auditor General of Canada" (Standing Orders of the House of Commons, 108.3.g), the PAC is the parliamentary committee most directly involved with the OAG. As Savoie notes, it is "the audit committee of parliament, and...it does not deal with policy matters" $(1990,33)$. The PAC reviews the OAG's reports, holds hearings on recommendations, interviews witnesses, and performs follow-up work related to OAG recommendations. It is the political connection between the OAG and Parliament, and performs a key role in the accountability process. While the OAG conducts audits and reports its findings, the PAC - as the political body reviewing those findings - has the power and platform to question and investigate the OAG's findings, attempting in the process to correct problems found by the OAG, or at the least wring commitments from those who can.

This section does not exhaustively detail the PAC's origins, history, and role. Instead, it offers a brief summary of the purpose and the duty of the PAC, especially as it relates to Parliament's accountability processes; the PAC's evolution is discussed; its relationship with the OAG explored; and finally, its effectiveness considered. While not perfect or without criticism, the PAC is a necessary partner for the OAG. Without it there would be little political impetus, short of public opinion, placed on addressing issues identified by the OAG.

Standing Committees play an essential role in Parliament's accountability process. The government makes decisions, and Parliament holds it to account for those decisions, in part through the scrutiny work performed by committees. With the help of the OAG, the PAC 
scrutinizes and holds the government responsible for spending that has already taken place. The PAC is essentially a committee dedicated to upholding financial accountability. By investigating the OAG's reports on government spending and program management, the PAC is able to use its political role to draw Parliament's attention to potential problems and areas that require further clarification or action from the government.

The history and evolution of the PAC predate Confederation, with the committee's earliest incarnation appearing in the mid-1840s in the Province of Canada (Dye 1984). From 1867 until the creation of the OAG in 1878 the PAC was the sole, de facto defender of the public accounts (Ward 1951, 56). It worked with the legislative auditor, John Langton, and its members - who did not necessarily have a background in accounting - had recourse to few other resources (ibid., 62). The early reports of the PAC apparently were quite effective, however, and its work contributed to the creation of the OAG and Parliament's revision of the audit process in 1878 (ibid., 67). In the period following the creation of the OAG, however, the PAC was not known for its follow up work, and its visibility suffered after the OAG began its role in the audit process (ibid., 76). Throughout the remainder of the $19^{\text {th }}$ century, the PAC was alternately known for its intense partisanship and preoccupation with sniffing out scandal.

The PAC experienced a major change in 1958, when the chairmanship of the committee was given to an opposition MP (Malloy 2004, 167). This had the apparent effect of increasing the committee's independence, as an opposition chair would be less bound by government pressure and party discipline. Savoie also notes that this may have increased its effectiveness and profile $(1990,32)$. Since then the PAC has operated in a largely static fashion, and the opposition chairmanship was formalized under Standing Order 106(2) in November 2002 (House of Commons Procedure and Practice, Second Edition). 
Relations between the OAG and PAC are generally framed as positive, albeit perhaps unbalanced. Franks notes that the two must work "hand in hand to ensure effective accountability" $(1987,239)$. While this is undoubtedly true, and the two rely on each other's specific strengths, a number of scholars have critiqued the PAC for being beholden to the OAG. Good (2007) and Savoie (1990) both note that the OAG often overshadows the PAC, due to the former's public profile and extensive resources. The general implication is that this relationship is backwards: the MPs should outshine the public servants, not vice versa. At least one past chair of the PAC critiqued the OAG as deliberately outstripping and ignoring its Parliamentary partner (Gauthier 1993). The OAG, due to its historical evolution and fundamental role, has undeniably emerged as the stronger of the two. The PAC, likely due to a number of systemic weaknesses in the Parliamentary system, has suffered from questionable levels of effectiveness. While the OAG and PAC need each other, and a good working relationship is considered the norm, there is little question as to which garners bigger headlines.

The PAC's effectiveness has been a longstanding subject of discussion, and many current criticisms facing it are mirrored in its early $19^{\text {th }}$ century days. Now, as then, MPs on the committee do not necessarily have a background in accounting. Partisanship is perceived as a recurring problem (Ward 1951, Franks 1987, Malloy 2004, Good 2007). The PAC is no exception to the usual litany of problems plaguing the committee system: high turnover rates, low priority for MPs, and little glamour or prestige (Good 2007). There is also some doubt as to what extent the government actually acts on PAC recommendations (Savoie 1990).

Yet the PAC does play a key role in the accountability process, as it provides the political outlet for the OAG's reports. It also serves to draw more attention to some issues - the "Sponsorship Scandal" comes to mind - in no small part by calling and interviewing witnesses 
before the committee in a public setting (Malloy 2004). These are functions that the OAG cannot carry out, and both can result in increased pressure on a government. While the PAC may be overshadowed by the OAG, and largely ignored by government and MPs, Savoie (1990) notes that its most important function may be simply to act as a deterrent effect. The PAC's very existence, and the possibility of appearing before it to explain oneself, may be a valuable disincentive that contributes to the maintenance of accountability.

What ultimately emerges from this historical sojourn is a picture of institutions that have, to some extent, changed while leaving a core task untouched. The OAG and PAC were each created to audit and review the Public Accounts of Canada, and provide Parliament with an important tool to assess government expenditures of public funds. In the intervening years the roles of these institutions have expanded somewhat, especially at the OAG, and they have come to occupy important places in the accountability process.

Of the two institutions, the OAG has undergone the greater change. The shift to VFM audits in the 1970s and the adoption of the Auditor General Act have permanently changed the OAG. Its mandate and scope have been significantly widened, in the process entrenching the OAG's function and statutory obligations. The stormy relationship between the OAG and government has largely subsided as the role of the former has been clarified; it has entered a period of relative calm, both politically and statutorily. A clear structure and format for the OAG has been established, limiting the ability of individual auditors general to challenge parliamentarians in the style of McDougall or Henderson. Despite - or perhaps because of - this limitation, the OAG's position is now widely accepted and respected. 
On the other hand the PAC, while gaining increased independence in 1958 with the move to an opposition MP as chair, suffers from a variety of historical challenges that have been present for decades. While more could be said on these struggles, they are of a different character more related to concerns of the 'democratic deficit' facing Parliament and the arguably inordinate powers of the executive branch of government. And yet despite the critiques and imperfections of each, the interactions of these two institutions combine to carry out a process that neither could do alone. 


\section{Chapter Three: Accountability, Auditing, and Financial Administration}

The OAG does not operate in a vacuum. Rather, it works as an agent of Parliament, ideally in cooperation with the government and executive branch. The OAG has historically been seen as an independent servant of Parliament - a conception challenged by some (Sutherland 1980, 2002) - and was designed to help Parliament maintain control over the public purse by auditing and verifying government expenditures. In this sense, the OAG aids Parliament as an agent of accountability: it provides the tools and information necessary for Parliament, generally through the work of the PAC, to hold government to account.

In order to fully grasp the work, role, and place of the OAG, including how these have changed, certain theoretical concepts must be explained, such as responsible government, accountability, Parliament's system of financial administration, and the audit process. These ideas underpin the operations of the OAG as an institution; without such objectives, there would be no role for the OAG in the first place. They provide the foundational wherewithal required for the OAG to remain a constant presence in Canada's financial and accountability structures, independent of the vicissitudes of political expedience. While it is not the purpose of this chapter to provide a normative conception of the $\mathrm{OAG}$ in these processes, the OAG's function is treated as a supplementary strength to Parliament's primary accountability function.

In accordance with the two main research questions being examined - the OAG's performance, and interactions with Parliament - this chapter first considers concepts related to Parliament, as this institution and its associated ideals fundamentally shaped - and indeed, created - the OAG. Second, to aid in the examination of the OAG's performance, auditing concepts are explored in some detail. 
Parliamentary Concepts: The Fundamental Role of Responsible Government

Before considering the theoretical subjects of accountability and parliamentary financial administration, a brief discussion on responsible government is required. This principle underlies Canada's parliamentary system, and occupies a key aspect of the accountability process of which the $\mathrm{OAG}$ is a part. The OAG must be understood in relation to the accountability of government to Parliament. As the OAG aids Parliament in holding government accountable, the question must be asked: how exactly is government held to account? In the Canadian context the OAG presupposes accountability, which in turn presupposes responsible government. How does this concept work, and how does it relate to the OAG?

As it pertains to parliamentary democracy, the idea of responsible government can be thought of in different ways. In The Parliament of Canada, Franks identifies three notions of responsible government: first, that the executive branch is responsible for the use of its power; second, that the government must responsibly guide a nation's affairs; and third, that "ministers are not only responsible for the use of these powers, but are also responsible and accountable to Parliament" $(1987,11)$. This chapter will focus on the third conception of responsible government. It relates most closely to the notion of accountability, and the executive's need to maintain the confidence of Parliament - two concepts of particular importance to the OAG, its role, and its relation to Parliament.

Government legitimacy is at the heart of the third conception of responsible government. In a democracy, governments are legitimate only if they operate at the pleasure of the people, or the people's representatives. If this pleasure is removed, a government cannot be said to be democratically legitimate. In order to maintain power in Canada's representative democracy, the governing party and its executive branch thus depend on the confidence of a majority of 
Members of Parliament (MPs). MPs can give or take away this confidence, legitimizing or delegitimizing the government. In this way MPs in the House of Commons are "the source of the legitimacy and authority of a government" (Franks 1987, 11). This is known as the confidence convention.

Aucoin et al. (2011) provide a similar assessment of responsible government in Democratizing the Constitution. While the executive branch controls the levers and direction of government, it is in turn "controlled by the people's elected representatives in the legislative assembly" (36). The authors link the initiation of this principle to 13th-century Britain and the evolution of Parliament. As democratic ideals spread, so too did demands that the government derive its power from the people it governed. Responsible government as a concept emerged, and now plays a major role in parliamentary democracies such as Canada's.

Ideally, MPs will scrutinize a government and its actions, and give or rescind confidence based on their findings and beliefs. However, government can compromise the ability of MPs to do so. As well, government operations have generally grown over the past century, and certain aspects of government (such as expenditures and estimates) may be too large or complicated for MPs to adequately scrutinize by themselves. In a political realm where MPs find themselves stretched between constituency commitments, party obligations, and Parliamentary work, is it possible for the requirements presupposed by responsible government to be adequately upheld by Parliament alone? 


\section{Parliamentary Concepts: Accountability}

A key aspect of responsible government is the notion of accountability. Franks notes that ministers are responsible and accountable to Parliament for the use of their powers. In seeking to maintain the confidence of MPs, ministers - and the government - must account for their actions and the exercise of their powers. This can be seen in various aspects of parliamentary business, perhaps the most obvious being the daily Question Period (QP). It also occurs in the work of parliamentary committees. This is where the work of the OAG directly supplements parliamentarians, as the PAC relies directly on the OAG to scrutinize government spending, and hold it accountable for that spending. Responsible government thus implies that a government as a whole, either through QP or committee work, is accountable to Parliament.

The concept of accountability is common in Canada and around the world, particularly in regard to politics. As a term it is used in various ways: 'the Minister must be held to account for her actions'; 'this government is not being held accountable'; 'who is accountable for this decision?'; 'we demand accountability'; and so on. While many are familiar with this term, and have a general idea of what it means, what concepts lie behind the notion of accountability, and what does accountability entail? Mulgan (2003) offers a broad definition:

'Accountability', the obligation to be called 'to account', is a method of keeping the public informed and the powerful in check. It implies a world which is at once complex, where experts are needed to perform specialised tasks, but still fundamentally democratic in aspiration, in that members of the public assert their right to question the experts and exercise ultimate control over them. (1)

In this sense accountability is a means to call 'to account' those in power. The Canadian Comprehensive Auditing Foundation (CCAF) defines accountability in a similar manner, as "the obligation to render an account for a responsibility conferred" $(1996,44)$. For the CCAF, 
accountability is closely related to the ideas of responsibility and answerability. Accountability is a synthesis of these latter concepts: it involves a formal process of providing an account - the answer - for a responsibility one has been given. Such an account can conceivably be satisfactory or unsatisfactory. Being held to account does not imply a job well done. Rather, it is an assessment of performance or a responsibility, and can have distinct outcomes.

Implied is a sense of explanation, or perhaps even retribution and punitive measures. For example, if a Minister were fired for improper actions, such a step would be a form of political accountability. Voters may use an election to hold a government to account by electing an alternative political party. Many similar examples can be imagined. As Mulgan points outs, accountability is a form of control by the public on those whom they have put into positions of trust and authority: it is a relationship between two parties. A government can be elected, or a person appointed, but it is the prerogative of the public to assess whether that government or person is acting according to their expected role and function. In turn, the public decides whether or not these actors should continue to hold power.

Behn (2001) expands on this concept of accountability as existing between two parties. He identifies two types of people in a system of accountability: the "holder" and the "holdee" (2). The former can be conceptualized as Mulgan's portrayal of the public - an actor(s) who calls another 'to account'. The holdee, in line with Mulgan's portrayal, is the actor in a position of power who is being held to account. The one party investigates, and the other party explains. Borrowing from the U.S. General Accounting Office, Behn notes that "Accountability is an important yet elusive concept whose meaning and characteristics differ depending upon the context" (ibid., 3). 
While accountability is inherently an undertaking that involves at least two parties, what else does it entail? Power (1997) identifies accountability as an inherent part of being a "rational individual" (1) and an important aspect of societal behaviour related to the issue of trust. Trust, he argues, is present to a degree in the majority of human society: a society devoid of trust is as rare as one characterized by absolute trust (2). Against this backdrop, Power notes that at the individual and organizational level, people interact, giving "accounts" or "communicative exchanges" (1) of themselves or each other. Since trust is present but not complete, such 'accounts' must be checked or verified from time to time. Thus, while it is rational to trust at times, it is also rational to be skeptical at other times.

Presupposed in Power's conception of accountability is the issue of expectation. Power himself does not address this, but Behn suggests "You can't have accountability without expectations" $(2001,7)$. In other words, actions presuppose motives, which in turn can be construed as expectations. When I act a certain way, I expect a certain result. When one actor interacts with another, both parties likely have expectations about what they will receive, and what the other will do. Implicit in these expectations is the trust that the action will carry out as expected. When such expectations are not met, or if they cannot - or must - be confirmed, then trust is compromised and the process of accountability begins.

Does accountability imply punishment, or merely explanation and verification? Behn emphasizes the idea of explanation. In examining various conceptions of accountability, he found that almost all focused on explanation, rather than punishment $(2001,4)$. While the popular conception of accountability might consist of wrongful actions justly punished, such actions are not inherently a part of the accountability process. The reality is more benign: actions must be justified and verified, but not necessarily vilified. 
Temporality is also related to the explanatory aspect of accountability. Does accountability require an unceasing examination of actions, or merely the permanent possibility of doing so, carried out occasionally? Mulgan conceptualizes accountability as the latter: it is the possibility of being called to account $(2003,10)$. In this sense accountability implies potentiality (ibid.); it does not necessarily have to be conducted to all parties at all times. The possibility of it happening, however, is a powerful "deterrent effect" (Behn 2001, 14). The mere possibility that an investigation of a party's actions can occur will likely discourage wrongful or improper behaviour.

Accountability, then, is a relationship between two actors. It involves expectations, a certain degree of trust, and a certain degree of skepticism. Some actions require no verification, and do not move beyond the levels of expectation and trust. Others require explanation, either because of unmet expectations or a lack of trust. One actor gives an explanation (account) of his or her actions; the other judges these actions in line with certain criteria or expectations. Often, perhaps, this is where the process ends: the account is verified, no wrongdoing is found, and the 'holder' exonerates the 'holdee', moving to the next examination. If wrongful actions are found if expectations or trust are abused, or perhaps unmet - then the action and holdee will most likely be corrected in some way. Accountability as a concept, however, is not linked to punishment per se. Accountability does not presuppose continual checking, but only the possibility of such action. It is important to note that accountability relates to the public and private spheres; this thesis will address it only in relation to the former.

One remaining issue that needs to be addressed is asked by Mulgan: "To whom and how should accountability be owed: to one or many?" $(2003,218)$. At issue is the scope of the accountability process and relationship: should accountability be a process between two actors, 
the holder and the holdee, or should there be multiple holders? To what extent should multiple overseers assess the actions of those who hold power? For Mulgan, the more parties there are concerned with ensuring accountability and verifying actions, the more likely the holdee - the actor whose actions are being checked - will act properly. Simply put, if different bodies are bringing different perspectives at different times to examine different aspects of your work, you are more likely to ensure that said aspects are carried out with propriety and due diligence. However, Mulgan also observes that as more holders are tasked with checking holdees, the more likely it is that some holdees will slip through the cracks due to oversight or miscommunication between holders (ibid., 198).

Parliamentary Concepts: How Does Accountability Relate to Responsible Government?

Now that the concepts of responsible government and accountability have been defined, what is their relationship? Returning to Franks' third conception of responsible government, that "ministers are not only responsible for the use of these powers, but are also responsible and accountable to Parliament" (1987, 11, emphasis added), his use of 'responsible' and 'accountable' must first be addressed. Does responsibility equal accountability, or do the words possess different meanings?

Mulgan differentiates between these two terms. One of the key aspects of accountability as addressed above is its exogenous nature. Two parties are involved in the process, and one examines the other. Responsibility, on the other hand, is the "capacity to act from free choice and with due concern for one's duties and obligations" (Mulgan 2003, 15). It differs from accountability both in its primarily endogenous nature, as well as its explicit lack of a requirement to be held to account. In other words, responsibility can be carried out by one party 
in relation to its actions; accountability presupposes the possibility of being held to account by an outside actor.

Given this distinction, one might suppose that 'responsible government' can be redesignated as 'accountable government'. Such a position, however, ignores the connection between responsibility and accountability. A government has power, and has a responsibility - a duty - to use that power in ways conducive to its intended usage. Such an approach corroborates the first part of Franks' account: that of ministers being responsible for their power. It also means that a government as a whole is responsible to Parliament for the intended usage of its powers. Certain expectations exist that government power will not be abused, and it is the duty of government to abide by these expectations. However, not only is government responsible to Parliamentary expectations, it is also accountable to Parliamentary expectations. If government fails in its responsibility, or if Parliament has reason to suspect wrongdoing, then Parliament can hold a government to account.

'Accountability' and 'responsibility' are thus the two interrelated keystones for the principle of responsible government. The two parties involved, Parliament and government, each have different obligations: government must answer to Parliament, and Parliament must question government. To borrow from Mulgan, government is the holdee, while Parliament is the holder, of accountability. As holder, Parliament can call government to account for its actions. If wrongdoing is found, MPs can withdraw their confidence in the government, forcing an election. As holdee, government must account for its actions. In this sense responsible government has two sides: the government fulfils its duties, and Parliament scrutinizes them. These are the respective burdens of the two actors. However, the onus rests upon Parliament to uphold 
responsible, accountable government. If the government lapses in its duties, it will probably be found out at some point; if Parliament lapses in its duty, who will scrutinize the government?

\section{Parliamentary Concepts: Financial Administration}

Now that the concepts of responsible government and accountability have been addressed, how do they relate to the government's system of financial administration? How does Canada's system of financial administration work? What role does the OAG play in this system? By employing Good's (2007) theoretical framework of guardians, spenders, priority setters, and financial watchdogs, this section will outline the basic premises of Canada's financial administration as it relates to accountability and the OAG. This section will not delve into the details of this process, but will outline a general view of the budgetary process as it relates to Parliament and the OAG.

One of the major duties of Canada's government is the passing of a yearly budget and estimates. This process is complicated, and ensures that the government cannot spend any money unless authorized to do so by Parliament. MPs must vote on the budget, the estimates, and budget implementation bills, thereby approving the government's appropriation of public monies from the Consolidated Revenue Fund (CRF). In theory, Parliament is the primary financial watchdog, tasked with scrutinizing government spending and holding it to account. In practice, Parliament's ability to carry out its scrutiny function is limited by numerous factors: partisanship, party discipline, the confidence convention, the complexity of the budget and estimates, and competing demands for the time of MPs, among others. These problems are well documented, and have been discussed, dissected, and lamented for over seven decades (Ward 1951); indeed, they have been traced back to pre-Confederation (ibid.). 
While the budgetary process may seem simple on paper, it is a nuanced and complex process that requires further examination. In 1964 Wildavsky proposed a theoretical framework for budgets and public spending in the American context that outlined two actors in the budgetary system: guardians and spenders. Guardians, broadly speaking, are actors - such as departments - whose role is to ensure the health of the public purse and limit profligate spending. Spenders, on the other hand, are actors who set out to spend public money. They could be departments, politicians, and so forth. As the framework was posited, these actors each assumed their roles, and the interplay and compromise that arose led to the creation of each budget, including who got what - whether the spenders were able to secure the funding they wanted, or if the guardians were more successful in keeping the purse strings closed.

Savoie (1990) and Good (2007) have used Wildavsky's framework to explain Canada's budgetary process. Savoie focused on explaining the steady growth of government spending. As others have before him, Savoie argued that Parliament plays little more than a superficial role in the budgetary process, for many of the reasons outlined above; it is not, then, a particularly adept guardian. Savoie notes exceptions, such as the Standing Committee on Public Accounts and the OAG. They do not escape his criticism, however, and he offers little endorsement of the OAG. Savoie was more interested in the federal budget rather than accountability per se, and what is most pertinent is his application of Wildavsky's framework to Canada's budgetary process.

Good (2007) updates and refines the guardian-spender framework as it applies to Canada by adding two new actors: priority setters and financial watchdogs. These four actors, Good argues, constitute Canadian financial administration's growth from an "old village" to a "new town" (4). Good uses Schick's (1997) three objectives as a starting point for outlining the budgetary process: maintaining fiscal discipline; allocating resources in line with government 
priorities; and, promoting efficient service delivery (21). From this starting point, Good outlines how 'priority setters' and 'financial watchdogs' have come to play a prominent role in the budgetary process: the former are mainly the Prime Minister's Office (PMO) and Privy Council Office (PCO), while the latter is predominantly the OAG. The remainder of this section will focus on the OAG as what Good terms the "financial watchdog".

Good describes the OAG's influence on the budgetary cycle as "indirect, long term, and subtle," $(2007,121)$. Unlike guardians, spenders, and priority setters, the OAG and financial watchdogs do not directly influence the creation of a budget. Rather, by investigating and reporting on past expenditures and budgets, and due to the publicity often garnered by such reporting, the OAG exerts pressure on the other budgetary actors engaged in formulating future budgetary expenditures. The assumption is that the other actors want to avoid what can often be considered negative publicity associated with financial watchdogs, thereby ensuring a degree of prudence is included in individual expenditures and the budget as a whole.

Despite this characterization of the OAG's influence, Good observes that it has unquestionably increased in the last three decades $(2007,37)$. This increased influence is attributed, in part, to the government's shift from line-item based budgeting to program and expenditure based budgeting. Other factors - such as the actions taken by individual auditors general, a steady refinement of budgetary practices, and a slow but growing public interest in the OAG - have also played a role in the OAG's increased influence. Perhaps most significantly, the adoption of expenditure- and performance-based budgeting programs such as Operational Performance Measurement System (OPMS) or the Policy and Expenditure Management System (PEMS), coincided with the passage of the Auditor General Act. Together these shifts paved the way for the OAG to transition away from simple financial budgeting and towards 
comprehensive, performance, or value for money (VFM) auditing. These auditing concepts are elaborated upon in the following section.

While the OAG's influence grew in part thanks to a shift in budgetary systems, Good theorizes that its status in the budgetary process is dependent on its influence, credibility, professionalism, and independence. The OAG can influence the public, Parliament, and the media by releasing reports on financial and performance audits of government spending and programs. While not always negative, instances of financial mismanagement often draw the attention of outside parties. The OAG's influence stems from its credibility. A lack of credibility would ensure that few trusted its findings, and this credibility is posited as the OAG's "most important asset" (Good 2007, 122). The OAG's credibility, however, does not simply exist, but arises from its professionalism and independence. Where professionalism "is about not making mistakes" (ibid., 123), independence directly relates to freedom from political influence and parliament. Without professionalism, independence, or credibility, the influence of the OAG on the budgetary process would wane.

The unique position of the $\mathrm{OAG}$ as financial watchdog almost necessitates occasional disagreement between it and the other budgetary actors. At the same time, however, Good posits that a healthy working relationship is required between the OAG, guardians, spenders, and priority setters (ibid., 132). If such a relationship isn't present, the financial watchdog will run the risk that the other actors ignore its recommendations. Despite the need for such a balance, the other actors expect the financial watchdog to pursue its duty, and call attention to any pertinent matters. This delicate balance is perhaps made easier by the OAG's 'outsider' status; in the event of disagreement, there is little need for compromise, as the other players don't depend on the OAG to the same extent they do on each other for budgetary approval (Good 2007, 132). 
Canada's budgetary process thus involves four general actors whose interactions contribute to the creation of the budget. These interactions do not happen at random, however. Rather, they are part of the government's annual 'financial cycle,' which runs from April 1 to March 31 of each year. While this cycle consists of numerous steps, only those directly involving the OAG and Parliament are discussed in this chapter.

Each year the guardians, spenders, and priority setters - all actors in the government help to produce the budget and main estimates. The budget is typically introduced in February, and the main estimates in March. The budget outlines general government priorities related to spending, while the estimates outline planned and proposed expenditures by department. These documents form the basis of the budgetary process; the guardian-spender framework outlines the actors involved in their creation.

Both the budget and main estimates are subject to Parliamentary approval. The former generally receives approval quickly, while the latter are submitted to Parliament for review by standing committees. This approval makes up part of the 'business of supply,' whereby Parliament grants the government the monetary supply it needs to carry out its budget and estimates. Parliament and the standing committees approve the main estimates, thereby granting supply and allowing the government to withdraw funds from the CRF.

Closing the financial cycle is the publishing of the OAG's annual report and the public accounts of Canada (Standing Orders of the House of Commons, 108.3.g). This phase of the financial cycle relates most directly to its built-in accountability measures; the OAG, Parliament, and internal auditors scrutinize departmental spending from financial and performance perspectives. More is said on these auditing processes below. The PAC does most of its work at 
this phase, working in conjunction with the OAG. While this is being done, the next year's estimates and budget are being prepared, and the cycle continues.

The financial cycle is the practical manifestation of the concepts discussed in this chapter. It is a yearly process undertaken by government and Parliament, in which the guardians, spenders, priority setters, and financial watchdog interact to create a budget and appropriate funds for public expenditure. Visible in this process are the concepts of responsible government and accountability discussed earlier. Both through the estimates, and more importantly the public accounts, Parliament scrutinizes the government's proposed spending, and actual expenditures, in the process getting an account from government for its actions. The OAG occupies an integral place in this process, as it not only indirectly pushes back against spenders, but also provides Parliament with the means to hold government to account. The final question to be addressed in this chapter is how the OAG carries out these roles.

Questions of Performance: Auditing, Accountability, and Financial Administration

This section briefly outlines the concept of 'audit,' and how it relates to the abovementioned processes of accountability and financial administration used by Parliament and the government. It does not provide an exhaustive analysis or history of auditing, but outlines the concept as it relates to the OAG: the types of audit used in Canada and their purpose, the growth of the performance audit, and their relation to the broader context of accountability and responsible government. An understanding of how these concepts work is important for investigating how their implementation and evolution have shaped the OAG's performance and interactions with Parliament. 
What is an audit, and how does it relate to the theories of financial administration and accountability already described? Traditionally, the concept of 'auditing' has been closely linked to the practice of financial accounting. As defined by the American Accounting Association, an audit is

a systematic process of objectively obtaining and evaluating evidence regarding assertions about economic actions...to ascertain the degree of correspondence between those assertions and established criteria and communicating the results to interested users (quoted in CCAF 1996; 224).

An audit can thus be thought of as a way of verifying or corroborating the financial statements of an organization to ensure their validity. This traditional conception of audit is narrow in scope, directly connecting it to the verification of financial accounts. Such an audit is known as a financial audit. These are conducted by numerous auditing organizations, both public and private, including the OAG. Such audits constituted the vast majority of the OAG's work from its inception through to the mid- $20^{\text {th }}$ century. Today, they account for approximately half of the OAG's audit work (Interview, April 7 2014). Since at least the 1970s, however, the meaning and use of the term 'audit' has been greatly expanded - in a way not devoid of controversy.

In addition to financial audits, the other major type of audit conducted by the OAG is now known as a 'performance audit.' In the words of the OAG, “performance auditing examines management practices, controls, and reporting systems with a focus on results, and making recommendations for improvement" (OAG Performance Report 2003/04, Intro, n.p). Lonsdale et al. describe the performance audit as "assessing aspects of how government organizations have performed and have used the resources provided to them" $(2011,4)$. Performance audits are thus not concerned with the attestation of financial statements per se. Rather, for the OAG, they are designed to assess the economy and efficiency of government programs, as well as examining whether government has in place systems designed to measure the effectiveness of said programs 
(Auditor General Act, s.7.d-e). The CCAF identifies two principles behind this type of audit: ensuring the best usage of public monies, and ensuring that those who manage these resources should be accountable for their "prudent and effective" use (CCAF 1996, 226). As the OAG's and Lonsdale's definitions suggest, there is longstanding debate on whether performance audits measure government performance, or rather assess how government evaluates its own performance; this distinction is explored further below, and in Chapter 5.

After a long, public battle between successive auditors general and the government, discussed in Chapter 2, the performance audit was included in the mandate of the OAG in 1977. At this time it was known as a 'value-for-money' audit, and during the 1980s and 1990s was called a 'comprehensive' audit. In 2004, then Auditor General Sheila Fraser described the switch to the performance audit terminology:

Recently, it became apparent that the term we were using for this type of auditing - valuefor-money - could lead to confusion about our role. It is ultimately Parliament's job to judge whether government programs are delivering value for money; it is our job to assess the performance of government in managing those programs. Thus calling what we do "performance auditing" is more accurate; it is also more consistent with international usage. (OAG Performance Report 2003/04, Intro, n.p).

The semantic differences between these terms are explored in Chapter Five in greater detail, but their terminological evolution has not drastically changed their purpose. Essentially, performance auditing assesses government programs. The OAG currently undertakes between 20 and 30 of these a year (OAG Performance Report 2008/09, 13), going into various government departments to assess the management, implementation, and control of a particular program. The use of these audits has grown dramatically over time, and they are not without their critics.

The traditional financial audit and the newer performance audit are the OAG's two most well known products. While there is wide acceptance of the former, the latter's growth has caused a considerable amount of controversy over time. Beginning shortly after the inclusion of 
performance auditing in the OAG's mandate in 1977, Sutherland (1980) criticized the lack of an objective methodology for this process. This has been a common observation over the years (see Aucoin 1998), as performance auditing lacks the clear-cut nature of financial verification. It has often been framed as a 'management study,' rather than a true audit. Steps have been taken in the auditing community to codify and improve the standards process for performance auditing, but this criticism has remained (for example, see Sutherland 2002 or Good 2007).

As seen in the above quote from Fraser, the performance audit has also been criticized as intruding on the role of Parliament. A common refrain addresses the perceived power such a process gives to the OAG at the expense of Parliament - the democratic watchdog and decisionmaking apparatus. This argument - that the introduction of performance auditing has caused government auditors to overstep their bounds - has had numerous incarnations over the years (Sutherland 1980, Savoie 1990, Power 1997, Aucoin 1998, Sutherland 2002). While this issue is addressed more fully in Chapter 5, a few words must be said here. Perhaps the main criticism of performance auditing is that it assesses the effectiveness of programs and comments on policy, which only Parliament is supposed to do. The Auditor General Act makes clear, however, that such audits can only determine whether government has established systems to monitor effectiveness, rather than comment on effectiveness per se (Auditor General Act, s.7.2.e). Regardless of the OAG's statutory limits, the dispute remains. Despite these criticisms, the performance audit continues to be used by the OAG. It is generally seen as serving a valuable purpose that stemmed, at least in part, from the object of traditional financial auditing.

Financial audits serve a distinct purpose closely related to the conceptions of accountability discussed earlier. For the CCAF, "the first prerequisite of audit is that it serves an accountability relationship $(1996,224)$. Financial audits verify that money has been spent on its 
intended purpose. They are intended to offer objective confirmation of an account provided from one party to the other; in Behn's terminology, audits serve the accountability holder by verifying information from the accountability holdee. In the case of Parliament, financial audits offer assurance that government has spent money as it said it would, and Parliament can use that information to hold government accountable for its actions.

Performance audits indirectly emerged from this process of accountability. Beginning under Watson Sellar, the OAG started reporting on 'non-productive payments' made by government. This led to a longstanding debate between government and the OAG over the propriety of such assessments, an issue fully discussed in Chapter Two. The final result was that the OAG should also report on issues of economy, efficiency, and government systems measuring the effectiveness of programs. While opposition parties, the media, and the public valued this information, the relationship between performance audits and accountability is not as clear-cut as with financial audits. The latter verifies whether the money was spent as intended, or not. The questions investigated by performance audits, however, can be more difficult to assess. For instance economy, or whether a service was purchased at the most economical rate, can be almost impossible to determine after the fact, as there can be few comparable benchmarks (Interview, February 6 2014).

Because of these difficulties, performance auditing reflects a nuanced view of financial accountability. Not only is it important that resources are spent as intended, it is also important that these resources were used economically and efficiently, and that government was able to assess their efficacy. For example, a financial audit will confirm that resources intended for staff training were spent as such. A performance audit, however, will ask whether the training acquired could have been achieved at a better cost, whether the resources spent were used with 
maximum efficiency, and whether government assessed the effectiveness of the training. Such considerations are now considered an important part of the accountability framework. This attitude is best summed up by the CCAF (1996): "although there may be some merit in doing the right things poorly, there is no redeeming value in doing the wrong things well." (119). In other words, while it's one thing to verify that money is spent as intended on a certain program, the question of whether the program is achieving its intended outcomes is a completely different matter. This again raises the normative issue of whether it should be up to Parliament or the auditors to answer such questions, which for want of a definitive answer must wait for another study.

Financial and performance audits thus form a key aspect of modern accountability regimes, especially in Canada. They are the tools of the financial watchdog, used to verify government spending and provide relevant information to Parliament for decision-making. In this sense these audits are a key aspect of both accountability and financial administration; they provide the objective assurance required for accountability, which in turn is upheld by Parliament in the business of supply and the follow-up that closes the financial cycle. Without audit, the accountability process in this regard would lack verifiability, and questions of financial probity and effectiveness could go unanswered.

This chapter has touched upon a number of overlapping principles and theoretical concepts related to Canada's parliamentary system of governance and the accountability, and the financial processes therein. At the system's heart lies the notion of responsible government, which itself presupposes accountability between the government, Parliament, and Canadians. Almost by necessity, government activity implies the expenditure of public funds, and in this 
sense government employs both guardians and spenders. Yet such a process cannot operate in a vacuum, and must adhere to the notions of responsible government and accountability. These concepts in turn are the building blocks upon which the OAG rests.

Acting as a servant of Parliament, the financial watchdog provides the information and assurance required to accurately hold government to account for its spending. Without this service, there would be little to no certainty regarding the expenditure of funds. As a result, accountability would suffer, and Canada's parliamentary system would fall under a cloud of doubt.

Without the foundation provided by these conceptual ideals, the OAG would lack the impetus, determination, and staying power required to carry out its mandate. Its institutional character draws upon these paradigms, which provide a degree of stability in the face of change. The notions of accountability, audit, and financial administration must therefore be taken into account when exploring how the OAG has changed over time. These concepts act as guideposts, and the OAG's institutional stability relies on them just as much as the legislation surrounding the office. 


\section{Chapter Four: OAG Performance Over Time}

This chapter directly addresses the first major research question of this thesis: has the OAG's performance and implementation of its recommendations changed in the last twenty years? What story do the OAG's reports tell over time? Is the picture one of consistency, alteration, or evolution? The OAG's reports are easily available, and, as per statutory requirements, reliably published each year. Yet, aside from the work of some employees of the OAG, little investigation has been conducted into the extent to which these reports, their contents, and their numbers have changed over time. At a time when auditing practices and the OAG both have their critics, several interviewees from the OAG - mostly senior officials expressed a sentiment that the OAG is concerned with the 'value added' it brings to the federal government. Is the OAG making valuable contributions to public administration and accountability functions? One way to answer this question is through an assessment of the OAG's recommendations. How many of these are implemented by the government, and has this changed over time? An answer to this question will provide insight into the OAG's operations, and, to an extent, the importance government places upon them.

To this end, Chapter Four investigates quantitative and qualitative data gathered for this thesis. The quantitative focus is on the Status Reports and Performance Reports of the OAG; each type of report is assessed in turn. The OAG's reports cover a wide variety of topics, and number in the hundreds of pages. As the focus of this research has been to assess broader trends and long-term change, the findings presented here focus on the macro level, eschewing the details of individual cases or audits in favour of overall rates of recommendation implementation. The qualitative focus is on those interview questions relating to the OAG's performance over time: among other subjects, interviewees were asked for their views on OAG 
procedures, recommendation implementation, and the impact of individual auditors general. Both approaches point to the same conclusion: OAG performance over time has experienced an evolution in methodology, but rates of recommendation implementation have remained steady.

\section{OAG Status Reports: Background}

The OAG's Status Reports (SRs) represent its formal follow-up on previous audits and recommendations. These have been published in a stand-alone format since 2002. Prior to 2002, follow-up audits were included as an additional chapter in the OAG's Annual Report of new audits. SRs provide an assessment and verification of work done by government on earlier recommendations, ranging from two to five years prior. While varying in length, SRs contain several chapters, each representing a specific follow-up audit done by a team at the OAG. The follow-up work contained in these reports and chapters was, and is, the OAG's attempt to make public the progress - or lack thereof - made by government on its recommendations.

The move to a stand-alone SR format occurred for two main reasons. First was the lack of visibility of follow-up recommendations: new audit findings tended to dominate and obscure any follow-up work and progress made on old audits (2002 SR, 2; Interview February 6, 2014). Given the long history of the media and public's interest in government spending scandals and 'horror stories,' such a pattern is understandable. Second, the new SR format utilized more rigorous criteria to assess government progress on OAG recommendations. Prior to 2002, most follow-up work relied on information relayed by government to the $\mathrm{OAG}$ - however, these early 'status reports' did not represent a bona fide re-audit of the initial audit and its recommendations. While progress was assessed via standards and criteria of reasonableness, these follow-ups ultimately relied upon unaudited information supplied by departments. The 2002 SR moved 
towards a formal re-audit of selected recommendations, in accordance with accepted auditing standards and best practices (2003 SR, i). This change represented an attempt to move away from departmental self-reporting, and towards a formal, comprehensive assessment of past recommendations - one that often resulted in new recommendations being made, and at times the audit of whole new programs or policies.

Due to this change, SRs since 2002 represent arguably the most reliable assessment of OAG recommendation implementation. Each audit selected for a SR, and, since 2006, each chosen audit's individual recommendations, has been re-audited and reassessed in detail and the findings published in a way that can be easily aggregated. Due to this reliability, the bulk of the data used in this section is taken from the OAG's SRs. Follow-up work prior to 2002 is addressed, primarily through data from Performance Reports, but the aggregated findings from that period must be understood according to their limitations, which are discussed in the following section on these reports.

While the post-2002 period represents the most concrete data for SRs and recommendation implementation, the reports themselves underwent a series of format changes from 2002 to 2006. The first SR enumerated and divided recommendation progress into six categories: completed, satisfactory, limited, no progress, rejected, and unknown (2002 SR Ch 1, 1). The SRs of 2003 and 2005, in contrast, did not publish data on individual recommendations; rather, they focused on a more qualitative assessment of the progress of the chosen audit, deeming overall progress as satisfactory or unsatisfactory. The 2006 SR somewhat cemented the SR format: the progress of individual recommendations was classified as either satisfactory or unsatisfactory, and the re-audited chapter as a whole was given a satisfactory or unsatisfactory designation. Furthermore, despite the stated desire of Ms. Fraser in 2002 (2002 SR, 1), the OAG 
did not issue a SR each year: reports are missing for the years 2004, 2008, 2010, and 2012. In interviews, these absences have been explained as the result of federal elections held in 2004 and 2008, and a dearth of resources in 2010 (Interview February 6, 2014). It is unknown why no SR was published in 2012 .

OAG Status Reports: Findings and Analysis

Due to these early changes to the SR format, a perfect year-over-year comparison is difficult to achieve. Despite these methodological inconsistencies, however, the following areas can be compared and analyzed: recommendation implementation, as measured by recommendations found satisfactory or completed; overall chapter progress; new recommendations; and government agreement with recommendations. Table One displays the aggregated SR data, focusing on these three areas.

Table One: OAG Status Report Analysis of Recommendation Implementation, 2002-2013

\begin{tabular}{|l|c|c|c|c|c|}
\hline Year & $\begin{array}{c}\text { Total } \\
\text { Recommendations } \\
\text { Examined }\end{array}$ & $\begin{array}{c}\text { Recommendations } \\
\text { found Satisfactory } \\
\text { or Completed } \\
(\%)\end{array}$ & $\begin{array}{c}\text { Chapters with } \\
\text { Overall } \\
\text { Satisfactory } \\
\text { Progress } \\
(\%)\end{array}$ & $\begin{array}{c}\text { Number of new } \\
\text { Recommendations }\end{array}$ & $\begin{array}{c}\text { New } \\
\text { Recommendations } \\
\text { with which } \\
\text { Government } \\
\text { agrees } \\
(\%)\end{array}$ \\
\hline 2002 & 20 & 30 & $\sim$ & 24 & 16 \\
\hline 2003 & $\sim$ & $\sim$ & 67 & 18 & 46 \\
\hline 2005 & $\sim$ & $\sim$ & 50 & 33 & 45 \\
\hline 2006 & 63 & 62 & 50 & 36 & 86 \\
\hline 2007 & 81 & 55 & 60 & 20 & 55 \\
\hline $2009^{*}$ & 40 & 63 & 40 & 12 & 67 \\
\hline $2011^{* *}$ & 38 & 72 & 67 & 17 & 100 \\
\hline 2013 & 25 & & & & 100 \\
\hline
\end{tabular}

$\sim$ Denotes information not available

* Overall recommendation numbers do not include two satisfactory assessments from the Commissioner on the Environment and Sustainable Development

** Does not include progress on audited projects; a sixth chapter is split as to whether overall progress was satisfactory or unsatisfactory 
As shown by the data in Table One, recommendation implementation rates have remained steady since SRs were implemented. While the data is unavailable for the 2003 and 2005 reports, the percentage of recommendations found satisfactory or completed has risen by an average of $32 \%$ since 2002 , and has remained in the mid-50 to low- $70 \%$ range since 2006 . The rise in implementation rates since 2002, however, must be interpreted cautiously. As it was the first SR written, and there is no data for the implementation rates in 2003 and 2005, it is difficult to know whether the 2002 result is actually representative of implementation rates at the time, or anomalous. The most important finding for this measure is the absence of an increasing or decreasing trend of recommendation implementation since 2006. Rather, the small fluctuations and steady range in this measure indicate consistent results in re-audited recommendation implementation at the OAG.

The assessment of overall progress on SR chapters has similarly fluctuated. While data was not available in 2002, between 2003 and 2013 the percentage of report chapters given an overall grade of 'satisfactory' has varied between $40 \%$ and $71 \%$. This value peaks every third report, followed by a period of relative decline. Both the cause and impacts of such an apparently cyclical finding are unclear. Despite such fluctuations, and a low point reached in 2011, the number of chapters given a satisfactory assessment has consistently remained with in the $50 \%$ and $70 \%$ range. This perhaps unsurprisingly mirrors the recommendation implementation rates, although the numbers for each category do not always directly correspond.

Some increases and decreases are evident in other aspects of the SRs. Total recommendations re-examined peaked in the 2007 report, and have steadily declined since. The number of new recommendations made in SRs has also fluctuated, although a decrease has been evident since 2006. It is difficult to draw conclusions from these numbers. It is possible, 
however, that such fluctuations are the result of other budgetary commitments at the OAG, or the focus of individual auditors general; in numerous interviews both areas were noted to impact the availability of resources for the follow-up process.

Apart from determining the causes of these fluctuations, an assessment of the normative value of re-auditing and concomitant new recommendations is equally difficult. It is possible that a higher number of re-audited recommendations is desirable, as this is the most reliable way to assess implementation rates. But such a position presupposes the value of recommendation implementation in the first place, and the benefit of the OAG re-auditing old work rather than conducting new work. The same can be said for the issuing of new recommendations. Given the OAG's finite budget and resources, not all of these options can be pursued.

One distinct trend in Table One relates to government acceptance of new recommendations. This category displays a consistent increase since 2002, albeit with fluctuations in 2005 and 2007. The percentage of new recommendations agreed to by government in 2002 is very low. This is possibly due to the introduction of SRs, and departmental and government adjustment to the SR format. In subsequent years, however, the acceptance rate has risen, reaching $100 \%$ in the 2011 and 2013 reports. Aside from the drop between 2006 and 2007, government acceptance of new recommendations has consistently been higher since the Conservative Party took office - especially since it gained majority status in 2011. While this observation does not indicate causality, one interviewee did speak of what was, in his opinion, the current government's tendency to agree with recommendations as a way to stave off controversy (Interview January 20,2014). Conclusive findings in this regard are elusive, but point to a potentially interesting trend. 
The trend depicted in Table One of government acceptance of new recommendations is an outlier. Slight fluctuations and relatively consistent numbers more generally characterize the findings in this Table. While questions of causation remain largely unanswered, the key takeaway is one of consistency. Table One - representing the most reliable data available for recommendation implementation at the $\mathrm{OAG}$ - presents a picture of steady recommendation implementation. The data reported in SRs do not necessarily represent a valid sample of the greater body of OAG recommendation implementation rates, a fact brought up in the interview

process; audits chosen for SRs are not subjected to, or selected for, tests of statistical significance in relation to the OAG's other audits. In this sense extrapolation is limited. Regardless, the sample points to steady implementation of recommendations over time.

Ultimately, notwithstanding their content, the SR format itself represents a change in performance at the OAG. The initial SR published in 2002 describes itself as a new method of monitoring recommendation implementation. Its results, especially when considered vis-à-vis OAG Performance Report data in Table Two, indicate a distinct change in the monitoring and assessment of recommendation implementation. This change can be viewed primarily as an evolution of OAG practices; while the results produced by this evolution have remained relatively steady, they signify a marked contrast to the era of departmental self-reporting on recommendation implementation.

\section{OAG Performance Reports: Background}

The OAG's Performance Reports (PRs) offer the most comprehensive assessment of the OAG's overall performance. These yearly reports address a wide variety of performance indicators such as budgetary goals, staff satisfaction, feedback from public servants and 
parliamentarians, interaction with Parliament, and recommendation implementation. While all valid indicators of performance, in keeping with the object of this project's research questions, only recommendation implementation rates and interactions with Parliament have been investigated; the latter are discussed in Chapter Five.

The sample of reports analyzed in Table Two runs from 1996/97 to 2012/13. The reports generally include multi-year data in an effort to show short-term trends. Of note, the data included in each report are generally based on the fiscal year rather than the calendar year. As a result some statistics - especially in relation to interaction between the OAG and Parliament change over time. This is due to the incongruence of fiscal and calendar years; for instance, a PAC report involving the OAG may not be published until April, even if based upon a meeting from January. Such a report would miss the PR's fiscal year deadline, and the relevant statistics would have to be amended in the OAG's subsequent PR.

This incongruity is one of two methodological obstacles related to compiling and analyzing data from PRs. Due to frequent changes made to the numbers, brought on by the fiscal year-calendar year distinction, conflicting numbers often arise year to year for a single value. For example, the 2006/2007 PR lists committee review of performance audits at $63 \%$ for the $06 / 07$ year, while the $2007 / 2008$ PR lists the review at $66 \%$ for the $06 / 07$ year. Such inconsistencies make it difficult to assess with certainty which number is empirically correct; in applicable cases, the appropriate range of numbers is presented herein, as opposed to a single value.

The second, and more significant, methodological obstacle relates to the validity of data presented in PRs. While PR data regarding Parliamentary interaction with the OAG is reliable, most of the data on recommendation implementation is not. With the exception of PRs since 2010/2011, all measures of recommendation implementation are largely based on self-reporting 
by departments. This method of follow-up was the norm at the OAG until 2002, which saw the introduction of SRs. The resulting implication is clear: much of the PR data on recommendation implementation are not independently verified. They are unaudited, and may be inaccurate to a degree. Despite this lack of reliability, the OAG did take steps to assess the reasonableness of departments' claims, and the numbers are for the most part consistent over time.

In addition to these two hurdles, the format of PRs has changed over time. Some indicators that were reported on are no longer used; some that are now were not in the past. The picture, in some areas, is incomplete. Methodological and personnel changes at the OAG, especially in the early 2000s, have also resulted in PR format changes. As a result, it can be difficult to establish long-term trends in certain areas, as there is no basis for comparison or measurement. The overall aim of the OAG's PRs, however, has remained the same, as has most of the data contained therein; this ensures that, for the most part, a comparison is possible. Despite these methodological challenges, PRs offer an interesting insight on recommendation implementation and Parliament's use of the OAG's audits. While the picture created by the numbers is incomplete and must be taken with a grain of salt, overall it presents a valuable representation of OAG performance over time.

\section{OAG Performance Reports: Findings and Analysis}

Contrary to the relatively consistent picture painted by Table One, clear, sustained increases and decreases related to recommendation implementation are present in Table Two. From the period of 1996/1997 to 2008/2009, PRs indicated a steady upward trend of full implementation of recommendations. While data is unavailable from 1998 to 2001, this progression is remarkably consistent, albeit with a large jump in 2001/2002. This increase, 
however, is accompanied by a similar decrease in the substantial implementation of recommendations over the same timeframe. Again, the data is missing for the 1998 to 2001 period. Although fluctuations are present in the latter measure, especially from 2004 to 2006, overall the substantial implementation of recommendations trended downwards.

Table Two: Performance Audit Recommendation Implementation Rates, 1996-2013

\begin{tabular}{|c|c|c|c|}
\hline Year & $\begin{array}{c}\text { Performance Audit } \\
\text { Recommendations } \\
\text { Fully Implemented } \\
(\%)\end{array}$ & $\begin{array}{c}\text { Performance Audit } \\
\text { Recommendations } \\
\text { Substantially } \\
\text { Implemented } \\
(\%)\end{array}$ & $\begin{array}{c}\text { Recommendations } \\
\text { Substantially or Fully } \\
\text { Implemented } \\
(\%)\end{array}$ \\
\hline $1996 / 97$ & 12 & 45 & 57 \\
\hline $1997 / 98$ & 17 & 37 & 54 \\
\hline $1998 / 99$ & $\sim$ & $\sim$ & 57 \\
\hline $1999 / 00$ & $\sim$ & $\sim$ & 60 \\
\hline $2000 / 01$ & $\sim$ & 49 & 65 \\
\hline $2001 / 02$ & $24-35$ & 19 & $63-84$ \\
\hline $2002 / 03$ & 45 & 16 & 64 \\
\hline $2003 / 04$ & 45 & 27 & 71 \\
\hline $2004 / 05$ & 44 & $35-38$ & $77-82$ \\
\hline $2005 / 06$ & $42-44$ & 26 & 72 \\
\hline $2006 / 07$ & 46 & 29 & 84 \\
\hline $2007 / 08$ & 55 & 27 & 90 \\
\hline $2008 / 09$ & 63 & $\sim$ & 90 \\
\hline $2009 / 10$ & $\sim$ & $\sim$ & 62 \\
\hline $2010 / 11$ & $\sim$ & $\sim$ & 72 \\
\hline $2011 / 12$ & $\sim$ & $\sim$ & \\
\hline $2012 / 13$ & $\sim$ & & 62 \\
\hline
\end{tabular}

The implications and correlations of this congruent increase and decrease are nuanced.

The data provided in PRs generally do not include hard numbers on recommendations unsatisfactorily or not implemented; as a result, it is initially difficult to say whether the decrease in substantial implementation is due to the increase in full implementation. Table Two's third column sheds light on this uncertainty. Showing the combined implementation rate for fully and 
substantially implemented recommendations, the third column depicts steady increases up until the 2009/2010 Performance Report. For the 1996 to 2009 period, the decrease in substantially implemented recommendations can therefore be attributed to a rise in fully implemented recommendations; recommendations transitioned from substantially implemented to fully implemented. The rise in the combined rate logically necessitates that over the period in question more substantially implemented recommendations became fully implemented, rather than regressing to an unsatisfactory state.

Two changes in Table Two's third column are important to note. First is the change in assessment of recommendations using a five-year timeframe, in use from 1996/97 to 2003/04, to a four-year timeframe used from 2004/05 onwards. This change means that, starting in 2004/05, only comparatively newer recommendations were being assessed for implementation. It is possible that the steady rise in implementation seen from the 2004/05 period to the 2009/10 period is due to a lack of investigating recommendations five years old or older. Some of the OAG's recommendations and audits relate to extremely complex government programs or areas of management. The recommendations of these audits are often the most difficult to implement; thus, by shortening the time frame used, these challenging, time consuming recommendations might miss the cut-off mark for follow-up, resulting in a rise in implementation rates. Such a possibility is hard to prove, however; other explanations - such as straightforward improvement of implementation rates, or unreliability of departmental self-reporting - are equally viable.

The second important change took place in the 2010/11 PR. In this report the OAG stopped publishing implementation rates based on departmental self-reporting, and instead switched to using verified SR data. The resulting drop in implementation rates is striking - from $90 \%$ to $62 \%$. The reasons for this methodological switch are discussed more fully in the 
following section, and the result is an abrupt end for the upwards trend of recommendation implementation seen in more than a decade's worth of PRs. As this change was relatively recent, only three PRs have been published using the new metric. To gain a longer-term perspective, the data can be compared with Table One; this provides a longer-term comparison of implementation rates according to departmental self-reporting on the one hand, and verified follow-up audits on the other. It must be stressed, however, that the data set from Table One are not a statistically significant representation of overall recommendation implementation. While PR implementation rates may have dropped in 2010/11 due to the adoption of SR data, it cannot be said that total recommendation implementation rates concomitantly dropped; the OAG has sacrificed reporting on a larger population of recommendations for verified follow-up work on fewer audits.

At this point an ambiguity should be addressed. Both the 2010/11 and 2011/2012 PRs show an implementation rate of $62 \%$ for their respective years. Each report notes the implementation rate was based on the 2010/11 SR (10/11 PR, 1; 11/12 PR, 16). The 2011/12 PR, however, lists the $62 \%$ for the $2011 / 12$ year rather than the $2010 / 11$ year. It thus appears that the data for 2011/12 is in fact based upon the 2010/11 SR. This matter is not resolved by the most recent 2012/13 PR, which only lists results for the 2011/12 and 2012/13 years. Despite this irregularity in reporting, when taken in conjunction with the analysis of Table One, Table Two's third column should reflect a relatively steady level of recommendation implementation.

As mentioned earlier, PR data regarding recommendation implementation should be approached cautiously. The switch to using SR data lends greater certainty to the data, even though the concomitant smaller sample may reduce its significance. The changes in recommendation implementation rates found in the OAG's PRs prior to 2010/11 cannot be 
completely verified. The changes to the report format itself, however, represent an operational change as the $\mathrm{OAG}$ fine tuned its assessment and reporting of recommendation implementation in its PRs.

Performance Over Time: The OAG Speaks

A number of questions remain from the previous analysis of recommendation implementation. Why did some of the methodological changes to the OAG's reports take place? What was the OAG's thinking behind the adjustments it made to its recommendation follow-up process? What role have individuals, such as auditors general, played in this regard? More fundamentally, how important is it that the OAG make recommendations in the first place? The interview process has helped to fill in these gaps, and provided valuable insights that the numbers cannot.

Interviewee answers also sometimes took a longer-term perspective than that available in the OAG's reports. Contrary to the quantitative dataset just explored, which focused on the OAG's performance since the mid-1990s, some of the interview responses draw on experience from the mid-1970s onwards; a handful of interview subjects had started at the OAG shortly after the passage of the Auditor General Act. In this sense, some of the responses provide a longer view of changes to performance over time. In line with the rest of this thesis, the concept of performance was conceptualized mainly in relation to the OAG's recommendations, their implementation, and the follow-up process as a whole.

Based on the themes emerging from the interview process, there appears to have been little overall change in the OAG's performance over time. Best practices have evolved internally in the Office, and the recommendation process - and monitoring of implementation - has 
changed accordingly. Somewhat unexpectedly, the question of who should be making and monitoring recommendations emerged as a contentious issue in the interviews. Aside from these minor changes and debates, however, drastic change has been conspicuously absent since 1977.

Although a status quo appears to be in place, in recent years important endogenous changes have occurred in the OAG's follow-up process. As the OAG has endeavoured to improve its own performance in this regard, a gradual evolution of best practices has occurred. This is clear in high-profile changes such as the adoption of the SR format in 2002, as well as less obvious changes such as an emphasis on using clearer language in OAG reports. Given the occasionally opaque nature of OAG reports, including a tendency to discuss change in generalities as opposed to specifics, it is difficult to address all the changes that have occurred; this section focuses on readily identified changes brought up in the interview process.

Of specific relevance to this project are changes made to the recommendation follow-up process. One interviewee from the OAG has extensive experience in this process, and provided a detailed summation of what he identified as three main phases of follow-up since the late 1980s. Initially, in the 1980s, the OAG would

follow up on somewhere around $60 \%$ of the recommendations we had issued, and we would follow up by actually going back into the departments and interviewing people and doing some document review to see evidence of the responses that they had made to our recommendations. That was pretty labour and resource intensive. It was done at a time when we weren't issuing as many audits as we are now, and what that was giving us was validation, our own validation of what the departments were saying they were doing (Interview November 29, 2013).

This process had to be changed due to shifting demands on the OAG's resources, and a growing prevalence in the publication of new audits rather than the performance of follow-up work. Yet, according to the respondent, this adjusted workload still proved too labour intensive, and the OAG switched 
into having departments provide us with information on how they were implementing our recommendations, and we were doing limited follow up on that. So we weren't going back into the departments and verifying a lot of that information, we were relying on our knowledge of the business, our general knowledge of what was going on there, to assess the reasonableness of the claims they were making. And we started to use that as our performance measure of how they were responding to our recommendations. This was purely self-assessment on their part with minimal reasonableness validation on our part. (Interview November 29, 2013).

This new process of departmental self-reporting coincided with the new SR format, and OAG references to departmental self-reporting are found in its reports as recently as 2010. SRs, of course, relied on actual follow up audits of earlier recommendations - a verifiable result. They only covered a small amount of audits, however, and self-reporting was used as a general benchmark. As a result of the switch to self-reporting, however

The departmental self-assessment rate kept crawling up. And our assessment was not; it was staying fairly steady at sort of $65 \%-75 \%$. Departments were getting up into the $80 \mathrm{~s}$, and so we knew we had an issue there, and so we stopped reporting that as public information in our Performance Reports. And then we switched to just using our own Status Reports so that we knew this information was good (Interview November 29, 2013).

As seen in the quantitative data, departments' self-reported implementation rates reached as high as $90 \%$ from 2008 to 2010 . Given the data provided by SRs, it is unsurprising the OAG shifted away from departmental self-reporting.

Now that follow-up based on self-reporting has been mostly abandoned, the interviewee estimated the OAG is performing follow-up audits on approximately $12 \%-15 \%$ of its audits, and this process confirms that between $55 \%-70 \%$ of followed up recommendations are completed in a timely fashion, a range corroborated by Table One. What is clear is that since the 1980 s the OAG, based on changing demands on its resources and concerns with the accuracy of its information, has significantly changed the way it performs follow-up on its performance audit recommendations. 
In addition to the changes in the follow-up process, the OAG has implemented a number of methodological changes to its general audit and communication procedures. The main changes discussed were mostly in relation to audit methodologies and standards, as well as communication practices. Given the criticism of the performance audit regime, it is perhaps significant to note that the OAG "conducts...performance audits to recognized professional assurance standards... we did that probably about twelve years ago, so a huge change there" (Interview November 29, 2013). While the adoption of standards for performance audits may not completely assuage concerns that performance audits are more akin to "management studies" (Good 2007, 128), it reflects what is likely a recognition at the OAG of the need to professionalize and standardize its performance audits as much as possible. As put by one former top official, performance auditing

initially was seen as being based more on opinion than rigorousness. A lot of effort was put in the last two or three decades in terms of perfecting the methodology for performance audits, so that they became more and more fact based and less judgmental. I think that that's where most of the progress has been made, and that counteracts certain criticisms at the level of the auditor general that he or she would be becoming too political, that value-for-money or performance audits were making political judgments (Interview January 22, 2014).

The extent to which this change will affect perceptions of the performance audit is unclear. For despite this shift towards formalizing the performance audit methodology, criticisms of it are still being made (Good 2007, Simmons and Nugent 2013).

More mundane shifts have also occurred as the OAG has adopted industry standards and new best practices. Electronic working papers were adopted, and an approach to improve communication by emphasizing clear, simple language in OAG reports also took place (Interview February 6, 2014). In addition, the OAG also adapted the audit methodology of consulting and audit firm PricewaterhouseCoopers in the mid 2000s (ibid.). The OAG and PAC 
have started to work together to promote the usage of action plans; these help to improve the follow-up process by outlining departmental responses and steps that can be taken to facilitate recommendation implementation (Interviews February 6 and 25, 2014). Their consistent use by the PAC, however, may be questionable. Internal auditors also use these plans for the same purpose (Interview April 15, 2014).

One final area in which respondents were asked about changes to the OAG's performance was the impact of individual auditors general - to what extent do these individuals affect the overall operation and priorities of the OAG? This question was asked of respondents who worked at the OAG, as it was believed they would have the most accurate perspective on the impact of any given auditor general.

On one hand, responses to this question focused on the OAG's processes and institutional momentum. In this sense, it was very difficult for an individual - even if he or she were auditor general - to come in and make drastic changes. As one employee at the OAG said,

We have some pretty tried and true processes and procedures in place that we use, and that doesn't change very much. So for one person to come in and say 'Gee, let's go and spend all of our time in national defence and don't worry about health,' that's not going to happen. Can they tweak a little bit on the margins? Sure. (Interview November 29, 2013).

One respondent echoed this sentiment, and reflected that the OAG's approach to auditing and choosing audits was performed best according to its prescribed course:

what we have is a very good process for identifying across government the types of things that we should be looking at...[An Auditor-General] could come in here and tell everyone 'I want to audit this, this, this, and this.' But [they're] only one person. If [they] rely on the process [they] have to look at risks, lots of thinking, lots of talking, and let the audits bubble up from that, that's a better way ...to manage it than 'I want to look at this and this,' or 'This is my priority or that is my priority' (Interview April 7, 2014).

These responses focused on the institutional procedures in place at the OAG. Over the years these processes have evolved, and it appears that they now shape the office and its direction to a 
large extent. The OAG and its employees, in deciding how to audit, rely more on tried and true procedure than any individual's agenda.

Other respondents focused on the impact of auditors general, arguing that it was quite significant. As one long-time senior official at the OAG said, "Each auditor general puts his or her imprint on the office and...improves the office's operations and the office's profile with Parliament and with the public" (Interview December 19, 2013). This response points to the impact an auditor general can have, and demonstrates that individuals do matter. Another respondent was even more emphatic:

it's called the Office of the Auditor General...the legislation governing that basically doesn't talk about the OAG, it talks about the auditor general (emphasis added) - shall do this or shall do that. It's very much oriented around the position, the individual. And when you read the media, or read accounts of what goes on in Parliament, it's always the auditor general said this, the auditor general said that. So the role, despite our best efforts to undo a bit of that, is very personalized. More so than many other public roles. And partly as a result of that, you know, the office is very much influenced by the priorities of the incumbent auditor general (Interview January 22, 2014).

A third official offered a similar take on the impact of auditors general:

when you come in as auditor general the work is already underway, so the first year or maybe even two, some of the work that you're presenting and tabling has been determined by your predecessor. But you can have a great deal of influence in the areas you want to look at, the approach you want to take.... So you can have, I think, an influence on the areas you look at. You can also have an influence on the way reports are done (Interview February 6, 2014).

Contrasted with the earlier responses, these two place a greater emphasis on the impact of individual auditors general; they paint a picture of an influential individual, who can direct the office in significant ways. Yet the institutional limitations of the office are still present. Auditors general are not all-powerful, even within their own office.

Ultimately what emerged from these interviews was an interesting split, as the tensions between actors and institutions clearly showed through. There was a general, although not 
absolute, tendency for employees of the OAG to downplay the impact of any particular auditor general, while auditors general did the opposite. When considering the question of an auditor general's impact on the OAG, the answer most likely lies in the middle: an auditor general exerts some influence, but must bend to the strictures of the OAG's procedures - be they recent or historical, conventional or statutory. And, as one respondent said, "Sometimes fate just takes over. For example, Ms. Fraser's mandate, her ten years were totally changed by the sponsorship scandal. Did she do anything different? Did we do anything different? Nope. Not at all. It just happened" (Interview November 29, 2013). Sometimes the auditor general exerts his or her influence, sometimes the office does, and not infrequently both must instead respond to the broader political environment.

Based on the quantitative and qualitative data examined, there have been no recent major changes to the OAG's performance, or drastic shifts in its mandate as a result of exogenous or endogenous forces. Nonetheless, it has experienced a degree of change resulting from internal pressures. This was reflected throughout many of the interviews, which were relatively uniform on these notes. However, when asked about recommendations and their implementation from a theoretical perspective, including how this area should relate to the OAG's broader mandate, respondents were much more divided.

Emerging from the interviews is a complicated and diverse picture on the role of recommendations in relation to the OAG's performance audit work. Every respondent, whether from the OAG, Parliament, or departmental audit offices, agreed that recommendations were important. After all, if a problem is identified, a solution should be proposed. The role of the OAG in such a process, however, was contentious; some interviewees believed that finding 
problems was more important, and that the recommendation process was neither normatively or

practically desirable for the OAG. As one former senior OAG official said,

I think the OAG should not make too many recommendations, and too specific recommendations. The Auditor General has to stay out of managing government, and the Auditor General has to draw the right conclusions as a result of their audit about something needing fixing. But how far you go in saying how to fix is a touchy question, an important question. I don't think the OAG should prescribe the exact remedy for fixing a problem, because then there's a danger of crossing the line into managing government. It's up to the bureaucrats to manage. And there's also a risk of being too prescriptive for a definite remedy for a solution for a particular problem. You may not have the best solution, and there could be a better solution around...I think the most important thing the Auditor General can do is put their finger on the issue, and keep the pressure on the machinery to fix the problem" (Interview January 22, 2014).

This quote gets at the heart of the matter, and touches on several important issues present in many of the interviews. Simply put, the OAG's expertise is in auditing. Its mandate is to audit, but not necessarily improve, government programs. While it is almost inevitable that auditing uncovers problems, it does not necessarily solve them. Rather, new steps must be taken to correct these issues. And this is where the process becomes complicated for the OAG, for finding and solving problems are two different issues.

One respondent, an executive in a departmental auditing office, pointed to the OAG's lack of experience and knowledge in the departmental programs it audits. This lack of expertise is not the fault of the OAG; there is no way it could have an in-depth knowledge of every aspect of government that it audits. But without this knowledge, is the OAG best suited to make recommendations for the issues it finds? As the above quote indicates, the OAG may not provide the best solutions to its clients. Indeed, if the OAG is so focused on auditing, there may not be sufficient time or energy put into the recommendation process, as another respondent indicated:

I think for a long time, the teams would do the audits and the recommendations would be kind of an afterthought at the end. There wasn't enough time spent thinking through the recommendation. And thinking it through with the department, because a lot of these are 
pretty complex issues. And the auditors don't always have the monopoly on what is right (Interview February 6, 2014).

Despite the potential struggles presented by these quotes, in the past few years steps appear to have been taken to solve them. The same respondent discussed how, during the past decade, the OAG had tried to work harder at making better recommendations, and understanding what was realistic for departments to accomplish. A current official at the OAG indicated they try "to only make recommendations when we feel an issue is important and serious enough that it needs to be fixed. Every recommendation we make is because we feel there's an improvement that needs to be made" (Interview April 7, 2014). There thus appears to be a sensitivity to this issue within the $\mathrm{OAG}$, and that it needs to be conscious of the recommendation process as an area for improvement. As noted, the OAG does not have a monopoly on solutions to problems. Furthermore, the possibility exists that the OAG could end up auditing its own recommended procedures in time; this could cause a conflict of interest, or at the least be an awkward situation, if the recommendation was found wanting.

Related to the issue of who should make recommendations is the question of who should monitor their implementation. There was no consensus in this area, and the question provoked a disparate set of responses. A number of respondents from the OAG felt that it should be up to departments or the Treasury Board of Canada Secretariat (TBS) to monitor and report on recommendation implementation. The key caveat, however, was that monitoring and implementation depended, first of all, on a department accepting the recommendation. Almost all respondents made this observation, best summed up in the following: "at the end of the day it's about the management of the departments, and it really is up to those departments and the deputy head. And once they commit to putting something into place, well they should make sure it gets 
done" (Interview February 6, 2014). This was a common refrain: once the government accepts a recommendation it should ensure the recommendation is acted upon.

Some respondents provided a more nuanced perspective, however. One retired official from the OAG observed that it was up to the OAG to monitor implementation, but "there's nothing to prevent departments from doing more on that" (Interview January 22, 2014). This was echoed by a current top official at the OAG, who envisioned the PAC, OAG, central agencies, and deputy ministers working together to monitor recommendation implementation. One Parliamentary official spoke at length on the issue of recommendation acceptance, saying that departments are

clearly responsible for implementing what they've committed to. Whether or not that meets the recommendation, I think it's still going to have to be the OAG to decide whether or not that recommendation is implemented by what the government has done. Then if the government doesn't implement its own commitments, that's another issue again...The OAG expects all of its recommendations to be implemented mostly because the government always agrees (Interview January 20, 2014).

Some respondents thus saw the possibility for cooperation in the follow-up and monitoring processes. For this line of thought, as long as the government agrees, there would - and perhaps should - be room for it to help the OAG in this regard.

Given these differences in opinion, no consensus appears to exist on the monitoring of recommendation implementation. It is entirely possible that the OAG has no official position on this issue; if it did, a more similar response would have been likely. While more research would have to be completed, it is quite possible the same holds true for the government. One outside observer questioned whether departments had the capacity to take on this role, expressing concern about the potential extra workload. He went on to say, however, that what is needed is a framework for follow-up on audits and their recommendations. 
The requirement of government agreement to recommendations, while essential, may now be used to quell potential controversies. Although respondents always posited government agreement as an important requirement for the monitoring process, it is possible that the government is now agreeing with more and more recommendations as a form of 'issues management.' To what extent does agreement signify a genuine intent to act, and to what extent does it reflect the government 'playing the game' in an attempt to reduce conflict when disagreement could actually exist? According to one respondent,

I've noticed that this particular government likes to say we agree with all the recommendations of the Auditor General and we've got an action plan to implement them. And it likes to do that for everything... There was occasionally, in previous governments, more of an attempt to push back on select issues. They usually ended up getting beaten up because the Auditor General does such a thorough job on their facts and so forth. But this particular government doesn't seem to push back at all, it's almost as a way of issues management. If you don't push back you can move on and forget about it (Interview January 20, 2014).

This question is particularly salient in regard to the findings on government acceptance of new recommendations in SRs, which has risen to $100 \%$ since 2011 . The actual implementation rate of recommendations, however, has generally remained below levels of government acceptance. It is possible, of course, that implementation rates remain lower due to the time required for remediation to occur. And the broader question also remains regarding the extent to which SR numbers reflect upon overall implementation rates; there is currently no reliable answer to this question.

Ultimately, for this area of the project, more questions than answers remain. Given the lack of consensus, these questions will likely persist until the OAG and government take more concrete action in an effort to clarify these issues. In the meantime, however, the dispute over recommendation monitoring only serves to muddy the waters of responsibility, lessening the 
likelihood of implementation in the process. As discussed by Mulgan (2003), should an accountability process take place between two actors, or many? If multiple institutions are involved in making recommendations and monitoring their implementation, it is possible that fewer errors will be made both initially and in the follow up process. Yet at the same time, as more actors become involved in this process, the more likely it is that some issues may paradoxically slip through the cracks.

The quantitative data presented in this chapter is mixed at best. Beset by methodological changes at the OAG, report formatting changes, lacunas in the available data, and uncertainties regarding correlation and significance, this chapter has attempted to provide a quantitative assessment of OAG recommendation implementation and any potential changes therein. Despite these challenges, definable trends and patterns have emerged. The OAG's performance has, by and large, remained the same. SRs depict consistent recommendation implementation levels for follow-up audits conducted by the OAG. PRs, while relying to an extent on unsound data, provide a supplementary perspective on these levels. The picture created by the OAG's Status and Performance Reports, while decidedly incomplete, points towards stable performance at the OAG. The interviews conducted have helped to fill in some of the blanks left by these reports, in the process corroborating the aggregated data. The question now becomes one of assessing the OAG's interactions with Parliament, as this relationship has an important bearing on the performance of the OAG. 


\section{Chapter Five: Interactions Between the OAG and Parliament}

The OAG depends on its interactions with Parliament. Without them, the OAG would not be able to table its reports, or communicate its findings to the public. Issues identified by the OAG would not benefit from the attention and scrutiny of the Standing Committee on Public Accounts (PAC), and its recommendations would not benefit from the political pressure directed by MPs towards departments, with the aim of fixing problems. For these reasons, and more, it is important to determine how these institutions interact, and whether this relationship has changed over time. An increase in interactions could indicate a heightened interest in accountability from Parliament; a decrease could indicate the opposite. The lack of sustained increases or decreases in a word, stability - would likely indicate a durable relationship between the two. While the research conducted indicates the presence of some endogenous and exogenous sources of change, by and large the interactions and relationship between the OAG and Parliament have stayed the same over time.

A combination of quantitative and qualitative data has been used to assess this relationship. Numbers from the OAG's Performance Reports (PRs) point to interactions that fluctuate yearly, but display no long-term trend of increases or decreases. The interview process, on the other hand, has brought to light a number of interesting themes. Related to the theory discussed in Chapter Three, the OAG wrestles with the 'watchdog' term. An important distinction was made on the OAG's assessment of program effectiveness, which bears consideration in regard to some of the prevalent academic literature critiquing the performance audit methodology, also discussed in Chapter Three. And a certain amount of change in the relationship between the OAG and Parliament was also brought to light: the effect of successive 
minority Parliaments on the accountability process, and changes to the PAC's organization, were both recurring issues that came up in the interview process.

The Duties and Role of the OAG: Is it a Watchdog?

Before exploring the relationship between the OAG and Parliament directly, a few preliminary issues must be addressed in order to shed light on the foundations of this connection. What do those involved with the OAG see as its primary duties? Does the theoretical conception of the OAG as financial watchdog, and its place in the financial and accountability structures of government, affect its relationship with Parliament? These questions are important to ask, as the responses solicited have a direct bearing on the presuppositions of this thesis, and contribute to the overall public discussion on the OAG's role in the federal accountability framework.

When asked about the most important duties of the $\mathrm{OAG}$, interviewees invariably discussed its audit work, and often its role in serving Parliament. This is unsurprising and indicates that the OAG's role, in essence, has remained the same over time. It audits government spending and programs, and provides those reports to Parliament. Financial audits and performance audits were both discussed, and these respective processes were often framed as being equally important products of the OAG. The OAG's less prominent work, such as its special examinations or work of the Commissioner of the Environment and Sustainable Development, were discussed less frequently. This contrast most likely indicates the difference in importance, or perhaps prevalence, attributed to these secondary features of the OAG - not only by the public, but also by the OAG itself. That being said, some senior officials also noted the importance of this 'secondary' work. 
The OAG's role in the accountability process and communication with the public were also prominent themes when discussing the duties of the OAG. A former top official at the OAG had this to say:

In terms of duties of the OAG, I think it's useful to go right back to the fundamental raison d'être for the OAG, which is to assist the Parliament of Canada in holding the Government of Canada to account (Interview December 19, 2013).

Another former top official at the OAG echoed this sentiment, emphasizing the importance of audits for providing necessary information to parliamentarians in this regard:

[Audits] give information to Parliament, that parliamentarians can use to hold government to account. So we really saw ourselves as being a source of information for parliamentarians on whether programs were being run well or not - whether they were in compliance with laws and regulations (Interview February 6, 2014).

These quotes point to the OAG's awareness of its role in the accountability process. Specifically, how the OAG must communicate the results of its audits to parliamentarians, who in turn use them to scrutinize government and hold it to account. Communication is key to this process, as another former senior official pointed out: "in terms of what you really have to do and do well is communicating the result of your work clearly to Parliament, and through Parliament to the public" (Interview January 22, 2014). The observation emerging from these perspectives is one of the importance not only of audit work, but communicating that work for the use of Parliament and the public. For what is the value of that work if no one pays attention to it? Particularly given the oft-technical nature of the OAG's work, the plethora of reports it issues, and the generally hectic schedules of parliamentarians, communication becomes a key role for the OAG.

The well-known 'deterrent effect' came up in relation to the OAG's role. One senior official currently at the OAG noted its duty in carrying out this often-mentioned feature of auditing: 
the fact that we do audits, whether they be financial audits or performance audits, helps to bring a certain level of deterrent effect. People know that there's a possibility that what they do is going to be audited and is going to be public information, and I think that helps bring a little bit more rigour into the system (Interview April 7, 2014).

The extent to which the deterrent effect is present is questionable (Morin 2004), and despite the prevalence of audits, problems continue to be found (Lonsdale 2011). Yet as one government audit executive observed, the fear of being audited is, to an extent, prevalent across departments and internal audit functions (Interview April 15, 2014).

The question of the OAG's role elicited similar answers among those who have occupied positions of senior management at the OAG. Not only is the actual audit work important, but so too is its communication to Parliament, which presupposes the goal of this information's use. The OAG's broader role as an accountability-enhancing institution also remains high on the list of its most important duties.

Performance audits were identified as an important part of the OAG's modern duties. These audits were discussed in every interview with OAG officials past and present. While it was consistently identified as a key duty of the OAG to conduct these audits, one area of distinct change observable in the OAG's reports and scholarly literature on audits is the shift in terminology related to them. The history of this term is addressed in Chapter Two, as it has changed from the 'value for money (VFM) audit' of the 1970s, to the 'comprehensive audit' of the $1980 \mathrm{~s}$ and $90 \mathrm{~s}$, to the current 'performance audit' of the $21^{\text {st }}$ century. But do these changes in terminology equate to a change in audit methodology and the duties the OAG carries out?

In discussing this terminological difference with OAG officials, a consensus emerged that, by and large, these changes in nomenclature have not translated to a significant change in substance. Put simply by one current employee of the OAG, "A lot of it is a difference in name. The actual nature of the audit has not changed significantly" (Interview November 29, 2013). 
Some difference was noted in regard to the comprehensive audit, which was seen as "the integration of attest work, compliance work, and performance audit work" (Interview January $22,2014)$. For the most part, however, the comprehensive and performance terms were seen in a synonymous light.

Perhaps the most important distinction was why the VFM and comprehensive nomenclature was abandoned. As one former top official noted, during their time at the OAG "we changed the terminology to call it performance audit, because people had the wrong impression that the AG was actually assessing the effectiveness of programs" (Interview February 6,2014$)$. This observation in large part mirrors the controversies of the 1960s and 1970s, during which the government and OAG were engaged in a highly public battle over measuring the effectiveness of programs - the value for money the public received from public expenditures. A current senior official offered a similar observation, framing the VFM approach as one that "really zeroes in on the cost-benefit analysis type question" (Interview April 7, 2014). Given the controversy surrounding the idea of VFM, and the argument that only Parliament should make such determinations (Sutherland 1980, Aucoin 1998), it is perhaps unsurprising that the OAG has moved away from this terminology. While a legitimate debate could be had as to whether a shift in terminology has resulted in a shift in behaviour, the above distinction regarding program effectiveness is an important issue that emerged as a major theme, and one that is often overlooked in the scholarly literature on the subject.

The measurement of program effectiveness has for a long time been a contentious issue in academic and government circles. Not only is it difficult to assess, but the question of jurisdiction - and who should make such judgments - has coloured the debate on the OAG in the post-1977 era. Numerous scholars have critiqued the OAG along these lines (Sutherland 1980, 
Savoie 1990, Aucoin 1998, Saint-Martin 2004). Although they vary, the most common criticism discussed charges that the OAG comments on policy by assessing the worthiness of programs via their effectiveness - essentially intruding on an area that should be the sole prerogative of Parliament.

Given this prominent academic debate, one of the questions asked of OAG interviewees was whether the OAG's approach to measuring the effectiveness of government had changed over time. The question was an attempt to explore conceptions of the Auditor General Act, which states that the OAG will report on any instances where it has observed that "satisfactory procedures have not been established to measure and report the effectiveness of programs, where such procedures could appropriately and reasonably be implemented" (Section 7.2(e)). In other words, the OAG is not mandated to assess government performance per se. Rather, it determines whether government has put in place its own procedures to determine program effectiveness. By aligning the interview question with the critics' position on the issue, a more detailed response from the OAG was hoped for.

Interviewees at the OAG invariably picked up on this distinction regarding the measurement of effectiveness. Each individual pointed to the OAG's mandate, noting that it is restricted from actually measuring or commenting on the effectiveness of programs. Some nuance was present, as one interviewee reflected that some change had occurred in this regard in the 1990s: "I think we basically introduced in our methodology a results dimension, which meant that you relied on more than just systems to come to conclusions" (Interview January 22, 2014). This was tempered by his recollection that the bureaucracy had also made a similar shift at the time. Despite this evolutionary possibility, there was unanimous consensus that the OAG does not actually assess effectiveness. 
A similar point was made on the charge that the OAG will comment on policy from time to time, and interviewees were asked what steps the OAG took to avoid this possibility. What emerged was an image of carefully constructed systems of review and feedback, as put by a current OAG official:

We have internal review panels that look at every audit that we design, and make sure that we are not going to cross the line. We often have external advisory panels, usually on the more complex, higher-risk audits. Often these people are providing technical advice, but one of the things they are doing is keeping us 'on side' policy questions like that... For some of the audits that are higher risk or higher profile we have a second level of review within the office, and then there's the auditor general him or herself who is certainly reading them from that perspective (Interview November 29, 2013).

One former official, however, reflected that to 'cross the policy line' occasionally may not be such a bad thing: "my view is that if you get accused of that once or twice in a serious way during your mandate, that's not so bad. And if you get never accused of that, maybe you're being too cautious" (Interview January 22, 2014). He also went on to note that the OAG does not want to get involved in politics or policy. Indeed, to do so would compromise the independence and credibility of the OAG that are so important to its prominence and position as posited by Good (2007), and discussed in Chapter Three. This is most likely the OAG's own personal 'deterrent effect.' While it may come close to commenting on policy from time to time, to do so regularly would be to undermine the very legitimacy the OAG relies upon to carry out its role, and maintain a relationship of trust with the public.

Despite the slight nuance in these answers, what has emerged is an important distinction that has direct implications for the academic literature on the OAG. While their points have some merit, too often have the OAG's critics conflated the assessment of systems to measure effectiveness with the measurement of effectiveness or performance itself. For example, Aucoin points out that the OAG has the ability "to comment on the government's efforts to report on the 
effectiveness of its programs. In short, the Office became an auditor of the government's performance writ large" $(1998,9)$. And yet, Aucoin's premise does not logically lead to his conclusion. The OAG reports on the adequacy of the systems the government has in place to measure effectiveness; it does not comment on effectiveness or performance per se. Measuring systems does not necessarily entail commenting on government policy. While the OAG - by its own admission - may get close to that line from time to time, such tension may not be bad. To move too far away from it would be to invite complacency in the audit function. To stray too far from the line one way or the other will have more serious repercussions than cleaving to it closely.

In contrast to the relatively uniform responses to the OAG's role and auditing practices, a clear contrast emerged on the accuracy and aptness of the 'watchdog' title used by the public and academics alike. As seen in Chapter Three, Good (2007) uses this term as a theoretical construct to describe the role of the OAG in the budgetary process, and the media have made repeated use of it in articles and editorial cartoons over the years. Many officials in government - especially in the $\mathrm{OAG}$ - expressed some frustration at this term. There are many perspectives on the notion of the watchdog. What emerges is a nuanced concept, rooted in a colloquialism, which defies easy conceptual classification. Given the prevalence of the term in popular and academic conceptions of the OAG, and its potential implications for the OAG-Parliamentary relationship, its applicability is important to consider.

Many interviewees from the OAG - both retired and current - took issue with the watchdog terminology. Most objected to the term, instead asserting that Parliament, given its official role of scrutinizing government spending and holding the government to account as per the dictates of responsible government, is the watchdog. Some, however, had little objection to 
the term, as the OAG assists Parliament in finding and addressing issues that require fixing. As one former top official at the OAG said, "It's a popular expression, and I don't mind it, because auditors general have to be good observers of the scene, have their antenna working and be vigilant and be ready to act if some issues pop up" (Interview January 22, 2014). This, however, was largely the exception to the rule, as most interviewees appeared to want to avoid casting the OAG as a watchdog, instead deferring to Parliament.

Former members of the PAC were also split on the term's applicability to the OAG. One former MP who had been involved with the PAC for a number of years said

I've always been a little uncomfortable with that term. It's slang, I like to stick to the audit, they provide the assurances, they do what they're supposed to do, I guess to a certain extent they're a financial watchdog. I know the financial watchdog term is used, but I like to stick to the more formal version (Interview February 5, 2014).

Another former member of the PAC offered a different opinion, however, agreeing that the OAG was a financial watchdog - even though it was perhaps unable to investigate every bit of government spending. The debate on the term was thus not confined to the OAG alone. It would seem a degree of uncertainty is present in relation to what the term 'watchdog' means, and how it fits into the accountability function and relationship between the OAG and Parliament.

Two interviewees questioned the term 'watchdog' itself, in an attempt to discern the semantics behind it. This level of analysis provided the most insight into this popular and theoretical term, as the term's implications were explored. The term watchdog, after all, relates to a well-known popular image - generally, the guard dog on one's property, waiting to catch intruders and wrongdoers, or at the least alert its owner to their presence. As one prominent academic in the field put it,

What does 'watchdog' mean? Well, let's look at dogs. All dogs have masters. They're on a leash. Dogs don't run loose. If they do, there are problems. It's not a lapdog or a junkyard dog, nor should it be. It has a master: Parliament (Interview March 22, 2014). 
This academic went on to further describe the OAG as the watchdog, versus Parliament as the watchdog: "It does provide a watchdog function; it makes things visible. It issues public reports, not internal government reports. Let's look at it the other way, considering Parliament as the watchdog. Parliament is more than just a watchdog. It has other roles" (Interview March 22, 2014). This account gets at the fundamental distinction made between the OAG and Parliament, and the watchdog function. Parliament cannot simply be thought of as a watchdog, as it has legislative and representative obligations beyond its scrutiny function. Likewise, the OAG in a sense really is a watchdog, as it reports regularly to its master, and knows its role. One current top official at the OAG took a similar approach, however, and arrived at a different conclusion, worth quoting at length:

You tend to think of a watchdog as somebody who only barks when something goes wrong, where I think if you look at our performance audits, we report whatever we find. We'll say that this is what's working right, this is what isn't working. Also, we don't have any bite. Lots of the time if you get caught by a watchdog you know it. All we have is the ability to say this is what the situation is, and then somebody else has to deal with it. It's not a term that I think really describes us very well, but at the end of the day it doesn't really matter because the popular press is going to use it anyway (Interview April 7, 2014).

From this perspective, 'watchdog' may not be quite the right term - unlike a stereotypical 'watchdog,' the OAG reports both good and bad results, and lacks the teeth to bite transgressors. Ultimately this distinction and debate matters little, as the above quote makes clear. For better or worse, the term has been ingrained into the public consciousness for decades. While its accuracy may be debated, there is little likelihood that the term will change. The OAG, and auditors in general, are seen as the watchdogs of the accountability process. The term may cause discomfort for the OAG, particularly when its public profile is exceptionally high due to the results of a particular audit or the reputation of a well-known auditor general. Yet the OAG 
undeniably shares some characteristics of a real watchdog. The limits of the term, and the obligations of the OAG and Parliament, must be kept in mind. The OAG is the financial watchdog of the budgetary system, albeit one without much bite, that pays attention to egregious and laudable behaviour alike.

\section{OAG-Parliamentary Interaction by the Numbers}

With these theoretical reflections in mind, the numbers behind the relationship between the OAG and Parliament can be approached with an appreciation of some underlying issues. The data depicted in Figures One and Two are culled from the OAG's PRs. These numbers relate to Parliamentary interactions with the OAG, and can be approached with greater certainty than PR data regarding recommendation implementation. The bulk of this interaction takes place via committee meetings and hearings, which the OAG can be asked to attend. As the OAG is an agent of Parliament, its participation in committee work - especially the PAC - provides its recommendations with democratic legitimacy and the heft of publicity seen as a hallmark and driver of the OAG's work. As with Tables One and Two, some gaps are present in the data. These are due in large part to formatting changes made by the OAG to its reports; some metrics have been dropped, changed, or added over the years. Despite these gaps, Figures One and Two offer an important insight into interactions between the OAG and Parliamentary committees over time. Without these all-important interactions, the OAG's work would not have nearly as much impact: it could not be tabled, examined, or acted upon by the public or parliamentarians.

Few long-term trends are present in Figure One. Rather, what the data present is a cyclical interaction between the OAG and Parliament. From 1995/96 to 2012/13, the number of Parliamentary hearings involving the OAG has dramatically fluctuated, in turn increasing and 
decreasing. Table Two shows the same for overall committee review of OAG performance audits; the data for only the PAC's review of OAG audits was incomplete.

Figure One: OAG-Parliamentary Interaction

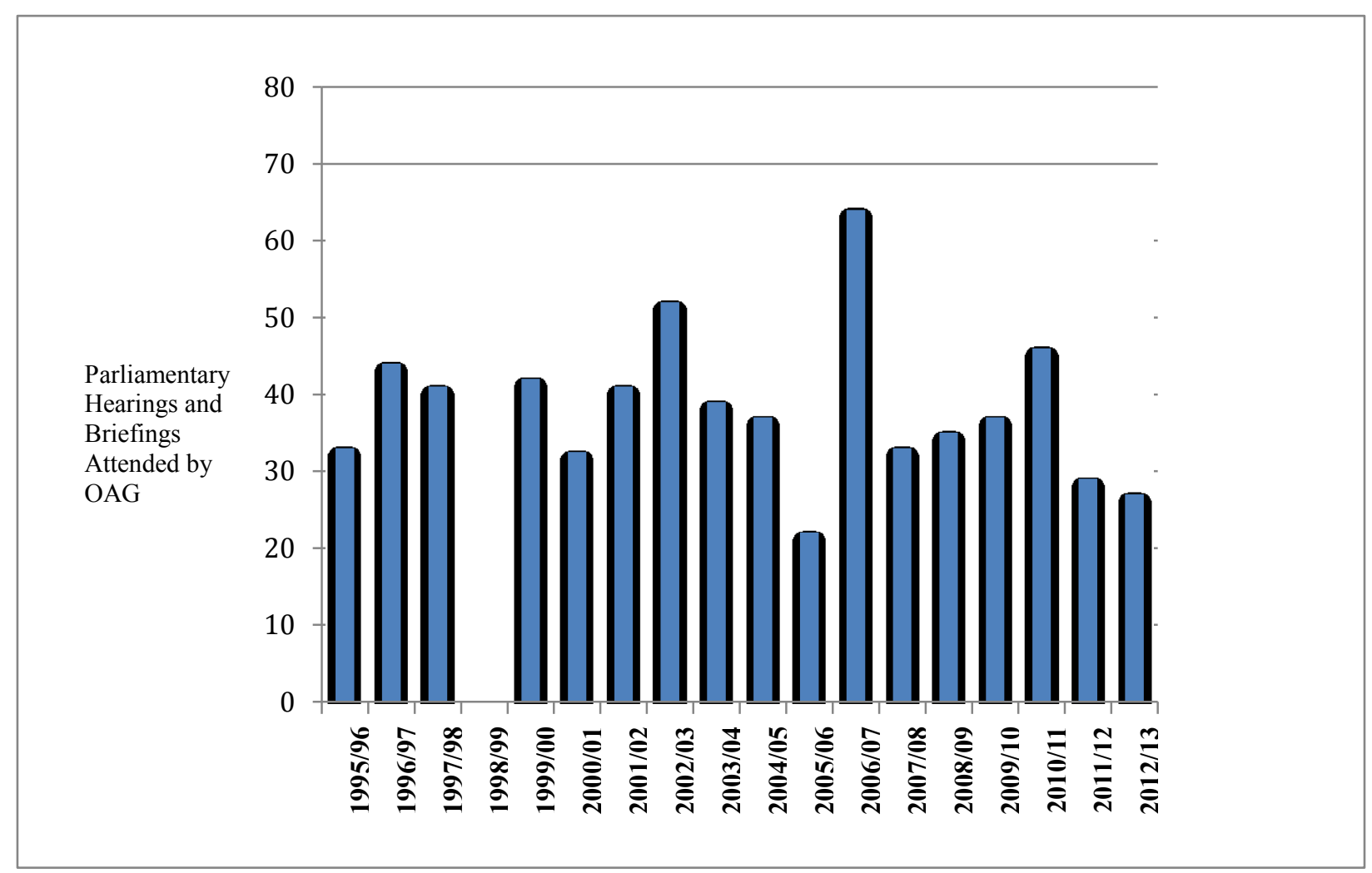

While the OAG's interactions with Parliament have not remained steady, or shown sustained increases or decreases, the resulting fluctuations present an interesting picture. OAG participation in Parliamentary hearings stayed within a steady range from 1995 to 2005, ranging from 33 to 52 interactions a year, for an average of 40 meetings a year (not including 1998/99, for which data was unavailable). This number dropped precipitously in the 2005/06 PR to 22 hearings, the lowest in the data set. This drop is curious, and there is no obvious reason for its occurrence. Parliament was in a minority at the time, a political situation which the qualitative 
research points to as cause for greater interaction between Parliament and the OAG. That the fewest interactions occurred in such a situation is unexpected; one would expect majority governments to curtail interactions with the $\mathrm{OAG}$, and minority governments to have the opposite happen. One possibility is the relative lack of parliamentary sitting days for the 2005/06 period - fewer sitting days results in less opportunity for interaction between the OAG and Parliament.

The 2005/06 drop was followed immediately by a sharp rise in $2006 / 07$, which saw the OAG participate in 64 briefings or hearings - the highest number in the data set. There are at least two plausible explanations for this dramatic increase. First, there were significantly more parliamentary sitting days than the previous year. While this would have allowed for more interaction with the $\mathrm{OAG}$, the parliamentary calendar included a similar number of sitting days in the 2001 to 2003 period, which did not see such dramatic spikes in interaction. The second possible explanation is the federal election of 2006, which saw the Conservative Party of Canada replace the Liberal Party of Canada as government. While there is no proven correlation between the two, it is entirely possible that the new government was politically motivated to use the OAG's work to uncover as many instances of the previous government's poor fiscal management as possible - especially in the context of the sponsorship scandal and the OAG's role in uncovering it. An appetite for enhanced accountability was prevalent at the time, which included the passage of the Federal Accountability Act, and a minority Parliament would have been able to maximize its interaction with the OAG. While these are all possible causes for the spike, it is impossible to determine its cause with certainty.

The heightened interaction in 2006/07 did not last. The following year saw a return to 1995 to 2005 levels, which persisted until 2011. That the OAG's interactions with Parliament 
from 2007/08 to 2010/11 - all during a minority Parliament - were similar to levels seen during the Liberal Party majority is again unexpected. This comparison casts doubt on the likelihood that opposition parties use their control of committees in minority situations to consistently interact more frequently with the OAG. If this were so, the period from 2006 to 2011 could reasonably be expected to produce sustained increases in interaction between the OAG and Parliament, rather than the single increase in 2006/07.

The final observation drawn from Figure One is the drop in interaction since 2011/12. Although not reaching the low of 2005/06, interactions between Parliament and the OAG have been at their second and third lowest levels for this period. As with all of the data regarding interaction between the OAG and Parliament, the question of causation is largely left unanswered by the quantitative data in OAG reports. Again, however, a political explanation is plausible. The Conservative Party won its first majority government in 2011, which gave the party the ability to fully control Parliamentary committees. The result could be fewer interactions between the OAG and Parliament, as the government attempted to limit the OAG from discussing sensitive matters in the public forum of Parliament, and the opposition from gaining political ammunition from OAG reports. Such a motive has repeatedly surfaced throughout the OAG's history (Ward 1951, Balls 1978, Sinclair 1979, Henderson 1984). Yet regardless of the cause behind the recent drop in interaction, if the fluctuations in the data set are themselves the trend, these low levels of interaction - in the absence of an unknown, new structural cause - will likely increase in subsequent years.

Also of note are the data shown below in Figure Two, which depicts Parliamentary review of the OAG's performance audits. Again, the data are characterized by fluctuations as opposed to sustained increases or decreases; in recent years, however, the data points to a 
relative decline of performance audit review. Whether this continues in the long term remains to be seen. That said, the fewest performance audits were reviewed near the beginning of the sample, in 1995/96; the highest percentage reviewed was in 2001/02.

Figure Two: Percent of OAG Performance Audits Reviewed By Parliament

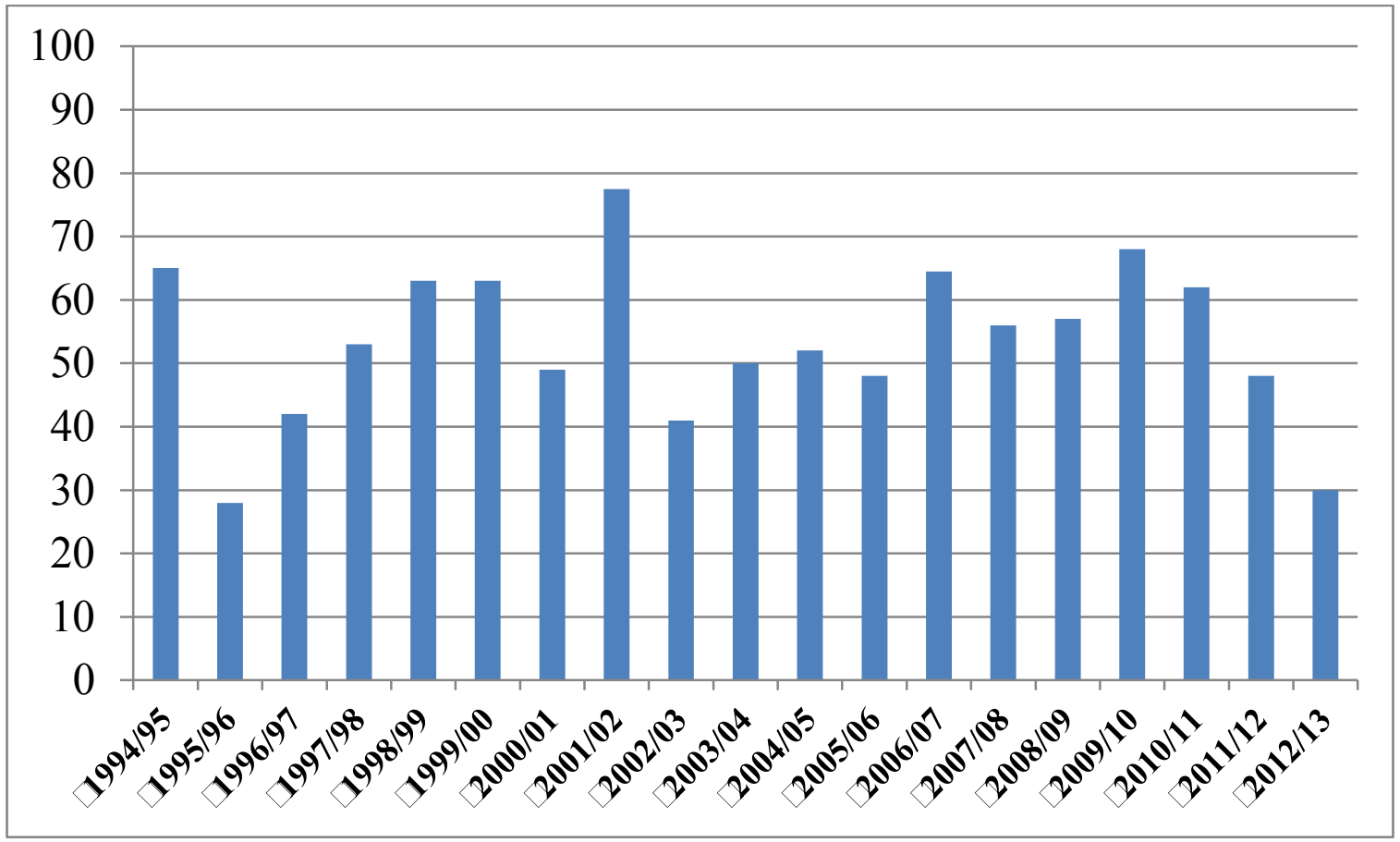

Perhaps the most important observation related to Parliamentary review of performance audits is a lack of correlation between it and the number of Parliamentary hearings or briefings involving the OAG. Years that saw the OAG participate in a low number of hearings or briefings could nonetheless result in a high percentage of audits reviewed, while years with a higher number of interactions might see a proportionally lower number of audits reviewed. For example, in 2005/06 - the year with the fewest interactions between the OAG and Parliament Parliamentary committees nonetheless reviewed $48 \%$ of the OAG's performance audits. The year prior saw 15 more interactions between the OAG and Parliament (a total of 37), but this led 
to an increase of only $4 \%$ of audits reviewed (a total of $52 \%$ ). Low levels of interaction between the OAG and Parliament might belie the amount of audits Parliament actually reviews.

The steady decline since 2009/10 in Parliamentary review of performance audits - the longest sustained drop in the data set - reflects upon the above. The number of interactions for this period has also dropped, although as shown in Figure One they increased from 2009/10 to 2010/11. This small increase in interactions, however, still resulted in a drop in the percentage of performance audits reviewed by Parliament. Taken with the above, this recent drop in Parliamentary review of audits is not necessarily a result of steady decreases in engagement between the OAG and Parliament. Fewer meetings between the two institutions does not necessarily lead to fewer audits reviewed. Instead, the explanation could possibly be a political one connected to the 2011 majority government, as the most precipitous declines since 2009/10 have happened since 2011 . This possible correlation to majority and minority governments came up in the paper's qualitative research, and is addressed in the following section.

\section{Institutional Interactions: The Inside Perspective}

Interviewees were asked at length about the relationship between the OAG and Parliament. Had it changed, and if so, what were the causes? The overall intention was to shed light on the second major question asked in this project; have changes at the OAG or in its performance been affected by changes in government? Such a connection is difficult, if not impossible, to empirically prove. Certain trends were noted in Figure One, which indicated varying levels of interaction between the OAG and Parliament. The causal relationship between these variables, however, is unclear. It is possible that such fluctuations were caused by variations in the Parliamentary calendar, for instance. In this sense, the variety of perspectives 
captured in the interview process provided a helpful level of detailed analysis in assessing this question.

A number of interesting themes emerged from this line of questioning, including the effect of successive minority governments, the 'turnover' effect when an election results in a change of power, and the effects of partisanship on the accountability process and the operation of the PAC. An impact on recommendation implementation, however, was not generally noted; neither was a difference in the reactions of the Liberal and Conservative governments to the OAG. While no definitive answer is provided to the key question of the political process' impact on the OAG, the interviews point to an ambiguous, multifaceted relationship that has nonetheless remained consistent over time.

The difference between minority and majority governments, and their effects on the relationship between Parliament and the $\mathrm{OAG}$, was the most frequently raised issue in the interview process. The period of minority government from 2004 to 2011 was, excluding the brief Joe Clark minority government of 1979 to 1980, the first time such an occasion has occurred since the passage of the Auditor General Act. The relative lack of government control in a minority setting - and the need for compromise between parties - is well documented. While governments are not powerless in such situations, the power of Parliament is understandably increased at government's expense. This increase in power was repeatedly cited as an impetus for increased OAG-Parliamentary interactions.

Given the unique position of the PAC in relation to the $\mathrm{OAG}$, the minority-majority dichotomy likely affected this relationship the most. Standing Committee membership is apportioned in accordance with party standings in the House of Commons. Thus, in a minority setting, opposition members outnumber government members on standing committees. This has 
the practical result of giving opposition members the ability to achieve objectives that could otherwise be blocked by a majority government. When asked about changes to the operation of the PAC, one former member observed,

I think it changed for the better, and I think one of the changes was that it was a minority government, that the government couldn't control the committee...I think there's a major difference between a minority government and a majority government. A majority government controls the committee, so they can make the committee process much slower, they can send it in different directions, within certain parameters they can do whatever they want. It's a different world (Interview February 5, 2014).

This quote highlights the difference in operation and ability that a minority situation imparted to the PAC. It had more control, and was able to interact more freely and constantly with the OAG. As one former top official at the OAG remarked, "it was a minority government, which meant that opposition controlled all the committees and that stuff. We were on the hill all the time. Constantly" (Interview February 6, 2014).

Given the lack of a complete data set, it is difficult to assess this claim in relation to the quantitative data on OAG-Parliamentary interactions. Yet to an extent, the perspective that minority governments interact more frequently with the OAG is borne out. Based on the data from Figure One, during the minority period the OAG participated in an average of 39 Parliamentary briefings or hearings per year. During the majority periods, the OAG participated in an average of 38 briefings or hearings a year. The highest and lowest number of hearings and briefings both occurred in minority years. Parliamentary committees reviewed an average of $58 \%$ of OAG performance audits during the minority years. During the majority years, committees reviewed an average of $51 \%$ of OAG performance audits. A degree of variation is present, but it appears that there has been slightly less interaction when a majority government is in power. While the overall difference is not that great, and many fluctuations occur, in the years since 2011 there has been a clear and steady decrease in PAC-OAG interaction. Throughout a 
number of interviews, a sentiment emerged that the majority government since 2011 has curtailed the PAC's interactions with the OAG. The quantitative data appears to confirm this. Yet some observations suggest the reduction in interaction has occurred in other, less obvious ways.

Until approximately two years ago, the PAC was directed by a small steering committee. As one recent member of the PAC said, the steering committee would meet in camera, and was responsible for setting the committee's agenda and general direction. For reasons the exact details of which no respondent was willing to discuss, the steering committee was abolished. One respondent did say "there may have been personality issues involved and there may be political reasons as well for certain incentives that apply or don't apply" (Interview January 20, 2014), but no more detail was provided. The result, according to one former member, was that the whole of the committee now had to use normal meeting time to decide upon the PAC's workload and direction. Another former committee member, whose experience stretched into the early 1990s, said that the PAC "always had a steering committee. One representative from each party. But again, the key was to build a relationship. Because it's easy for a committee to dissolve into acrimony, and you don't want that. It just means it becomes dysfunctional" (Interview February $25,2014)$. The general consensus, it appeared, was that the abolition of the steering committee for whatever reason - has negatively impacted the ability of the PAC to interact with the OAG. It appears the PAC's efficiency has been negatively affected by this change, and in its place partisan debate has become more prevalent.

This reduction in interaction between the two is particularly troublesome, as nearly all respondents spoke of the importance of the OAG-PAC relationship. As one respondent said of this relationship, 
I think there's a bit of a symbiosis between the two, so I think it's vital. The OAG would have less of an impact if it didn't have a parliamentary committee to bring attention and focus to its studies. So the sponsorship report might have had some attention, but having a committee bring in officials day after day after day and constantly keeping it in the news and in the media gave it so much more oxygen than it otherwise would have had (Interview January 20, 2014).

While the sponsorship scandal itself predated the Martin minority government, it was under Martin that the Gomery Commission was struck. The above quote is a perfect example of the importance of the OAG-PAC relationship. The visibility of an issue that was very important to Canadians depended, to a certain extent, on the work of the PAC. For if the OAG's report had not been subject to Parliamentary investigation, its impact might have been limited, or perhaps hardly felt at all. It is impossible to say that majority governments will uniformly politicize or hamstring the PAC, yet the possibility does exist for this to happen.

Aside from the effect on the PAC, some respondents argued that minority governments necessarily respond in different ways to issues of political concern. This is unsurprising, as the governing party must rely on the support of opposition members. Governments in general are not always the most friendly towards the $\mathrm{OAG}$, as it has a tendency to unearth scandals that some would prefer be left to lie. As one former official said,

after the sponsorship audit, let's just say the OAG wasn't the most popular place in town. Because we created work for people, attention for people, a lot of focus on government that was not always appreciated. Now that, you can sort of understand in a way, but there were some very good people who understood this is the job we had to do: you report what you find. But the government was not happy with that audit. And there have been other times too, with certain audits, that some people are not happy that these things come out, because it does create public attention, and there's a certain political fallout I guess, to some of them (February 6, 2014).

This observation could apply to numerous situations in the OAG's history. Its audits, time and again, have embarrassed governments of various political stripes. When the government in question was in a majority position, it was better able to control the situation. If it were a 
minority, however, the entire political calculus changed. In these cases, Parliament would have much more leeway to interact with the OAG in ways it saw fit. The PAC would be better able to investigate a particular issue, interacting with the $\mathrm{OAG}$ more regularly and reviewing more of its audits.

In attempting to determine the cause of this change, there are two possible, and likely mutually reinforcing, explanations. On one hand is the minority-majority dichotomy. The mechanics of Canada's parliamentary system allow a majority government to better control Parliament's institutions, including the committee system. Through this control, majority governments are able to indirectly control the OAG, or at least minimize its influence. This can especially be seen in the possible 'issues management' approach to agreeing with all of the OAG's recommendations. Doing so may help to reduce conflict, and possibly improve the government's standing in the eyes of the public. Yet if recommendations are agreed to and not acted upon, this short-term response to the OAG could backfire.

On the other hand is the question of partisanship. The role of political parties was not fully explored in the interview process, but one former member of the PAC mentioned it in relation to the PAC's ability to conduct its work. Although the party system is inherently connected to Canada's system of governance, the effect of partisanship on political competition must be remembered. Given the PAC's long-standing history of scandal hunting for political advantage (Ward 1951), it is unsurprising that party members would do all they could to minimize or maximize this possibility, depending which side of the House they sat on. Partisanship is always present in the House of Commons, and has a direct connection to the question of political power. In a minority setting, it enables scandal hunting and engagement with the OAG. In a majority setting, it reduces this capacity. 
While partisanship is always present, governments generally change on a regular basis.

And yet, according to a number of respondents, when the switch occurs between opposition and government, accountability-seeking behaviours may be slow to catch up. These switches in power have two important outcomes. First, according to a former senior official at the OAG,

we normally enjoy a honeymoon when there's a new government elected, and that stands to reason. You're dealing with issues that were all the problems caused by the previous government for a little while, until you start coming up with new ones for which they're responsible... whether you want it or not, you are more popular with the opposition than with the sitting government. And then one day the opposition comes to power, well it carries on over for a little while until you start coming up with new stuff (Interview January 22, 2014).

As early as the 1890s, some version of the 'honeymoon effect' was present between the OAG, PAC, and a new government. A new government would be elected, and use the PAC to dig up scandals that made the previous government look bad. Ward used the exact phrase 'honeymoon' to describe it, noting that such a phase fades over time (Ward 1951, 114). While the quantitative data examined fails to clearly corroborate this opinion, its prevalence over time lends it validity. Even if the motives of a new government may be less than noble in this regard, it appears that it is likely to engage more with the OAG early in its mandate.

Second, and closely related to the honeymoon effect, is what could be called the 'turnover effect.' As one former OAG official noted, when a new government comes to power, it may still act like the Opposition - hunting scandals. And the Opposition, knowing that such scandals may arise, try to avoid such scrutiny:

when the Conservatives came in in 2006, there were obviously a lot of new people who had not served in Parliament before, who were quite frankly used to being in opposition...in some of the committee hearings, you almost felt like reminding them that they were now the government... what happens of course is when parties change in government, the Liberals after 2006 wouldn't be asking really critical question on some of the audits, because it was stuff that happened under their watch. So it took a couple of years before they would actually start to ask the really tough questions (Interview February 6, 2014). 
Of course, the honeymoon effect and turnover effect would have an inverse relationship. As the honeymoon ended, and the new government had more to worry about, the opposition would become more strident in uncovering new issues. This is a clear example of how changes in government have the potential to affect the operations of the OAG and its Parliamentary interactions.

Despite the effect of majority and minority governments and electoral turnovers on the OAG, its relationship with Parliament and successive governments has largely remained the same. As one former top official with the OAG said, the OAG, from the point of view of its public profile, can seem to be an important organization. But do I think that a prime minsiter or a cabinet of a Liberal or Conservative government has a big discussion about how it's going to deal with the OAG? We're not that important, we're just auditors (Interview December 19, 2013).

Based on the academic literature and the research conducted for this project, governments of all political stripes have had various relationships with the OAG. While this relationship has at times led to change, by and large such events appear to be the exception rather than the norm. The two factors that appear most salient are the majority-minority and opposition-power dichotomies. These situations have the ability to shape how Parliament and parliamentary actors respond to the OAG. Such situations can determine the frequency and quality of PAC-OAG interactions, as well as the position of political parties on the need for such interaction. The relationship between the OAG and Parliament appears stable, and has little profound effect on the former's performance and the recommendation implementation process.

While interviews cannot provide a definitive answer to the questions being asked of the OAG, they do offer a series of snapshots that provide important insight into the last twenty years 
- and more - at the Office. These snapshots have supplemented the quantitative research undertaken for this thesis, and have produced answers beyond the scope of the numbers in the OAG's reports.

For the most part both the qualitative and quantitative data sets have arrived at the same answer, albeit by different means. Over the past twenty years, it appears the OAG's relationship with Parliament has largely remained steady, and immune from any dramatic political change. The effect of minority governments on this relationship, however, is particularly salient, and is deserving of greater research. The honeymoon effect has been present for over one hundred years. Although it is nothing new, its continued existence is an important indicator of both a lack of change, and the likelihood of increased OAG-Parliamentary interaction in the early years of a government's tenure. Despite the picture of stability that has emerged, the possibility exists, of course, that greater change could occur to these interactions and relationship in the future. Chapter Six explores a few tensions that have emerged between the academic literature and the research conducted for this thesis, what this research may mean for the OAG, and prospect of future change at the Office. 


\section{Chapter 6: From Change to Stability}

Despite its tumultuous history, almost all signs point to a period of relative stability for the OAG in the last twenty years. While some change has occurred, it has been either an endogenous adoption of best practices, or else the tweaking of statutes. To be sure, some prominent legislative changes have been made - for example, the addition in 1995 of the Commissioner of the Environment and Sustainable Development to the OAG - but these pale in comparison to the period of change in the 1970s. Recent changes have also largely been free of controversy. Indeed, the OAG as a whole appears to have entered a period where it is largely beyond reproach. While some scholarly criticisms remain, by and large recent governments have shied away from combat with the OAG, a stark contrast to the governments of the 1960s and 1970s. The public and media appear favourable, as usual, in their inclination towards the OAG. This controversy-free phase is no doubt due in large part to the OAG's cultivation of its independence and credibility, as put forward by Good (2007). The result is a relationship between the OAG and government that is predictable, although not necessarily comfortable.

The research conducted for this project has been exploratory in nature. The questions raised have not been definitively answered. Despite this lack of empirical certainty, a number of key issues have been brought to light, including a few that challenge prevalent academic conceptions of the OAG's work and role. At the heart of this project has been an underlying question of the OAG's impact on, and value to, government: how has it performed, has this performance changed, and how could it improve? The relationship between the OAG and Parliament was also questioned, and what emerged was a picture of reciprocity, a degree of nuance, and by and large stability between two institutions. In assessing the extent of change at the OAG within the last two decades, it would appear that the OAG has become a political 
institution in the classic sense. Its statutes and history have established a solid framework and expectations, and the actors within recognize it; the structure-agency paradigm shows through. This concluding chapter ties together these major themes, and offers final insights on the OAG's performance, both historical and current.

\section{The OAG's Impact and Value}

While in this case a lack of change may be an indication of stability, an important issue stemming from this analysis is the OAG's impact. How have its audits affected government, or have they at all? From the OAG's Status Reports (SRs), it is clear that at least some recommendations are implemented. While the statistical significance between the SR sample and the broader pool of recommendations is unknown, it is not unreasonable to expect a degree of correlation. As one interviewee noted,

The follow-up system is consistent across the large departments. No one wants issues or bad press... We consult the client in making our recommendations. We want a recommendation that works for the client, that is achievable and cost-effective, but also addresses any issues we find (Interview April 15, 2014).

Given the occasional discovery - and public exposure - of government mismanagement, this desire to implement reasonable recommendations and solve problems bodes well for the audit process. Not all recommendations get implemented, or have an impact on government operations. And in this regard, there is likely room for improvement - both within government, and the OAG. Legitimate disagreement on recommendations is bound to occur, and is not bad per se. Yet if the OAG wants to maximize its impact, and improve public management through the audit process, it must continue to ask how it can improve its operations.

Two respondents from the OAG raised this question a handful of times in the interview process. As one senior official at the OAG asked, "how do we know that we are adding value?" 
(Interview April 7, 2014). This appears to be, at the least, a current theme at the OAG; perhaps it is turning its powers of evaluation on itself, in an attempt to determine its own performance and how it can be improved. The OAG's Performance Reports (PRs) have addressed this question for a number of years, and their continued prominence suggests that issues of the OAG's place in, and value to, government continue to be questioned in an effort to improve itself.

Measuring recommendation implementation is but one way to assess this issue. At the end of this thesis, a number of questions remain regarding this metric. As brought up in Chapter Four, would an increased emphasis on follow-up audits result in higher implementation rates? Or, alternatively, does the value of new audit work outweigh a heavy emphasis on SRs and follow-up audits? As more than one respondent indicated, a single new audit could actually result in several follow-up audits, if every aspect of its implementation were to be assessed. This balance, and the need for assurance, should be scrutinized. To what extent should the OAG rely on departmental self-reporting of progress, and to what extent should it investigate every last aspect of its recommendations? Ultimately the question comes back to theoretical conceptions of the accountability process: how much should the word of those held accountable be trusted, and how much should it be verified? There is likely a middle ground, but it is beyond the scope of this thesis to say whether the OAG currently occupies it.

The work of Danielle Morin raises important questions in this regard. Her 2004 assessment of the impact of performance (or VFM) audits in the federal and Quebec governments leads her to conclude that audits - and sometimes often-repeated audits - are no guarantee of good management. While she concludes that VFM audits have had an overall "positive influence on management of audited organizations" (Morin 2004, 162), a degree of doubt is cast on the extent of their impact. Of note, her research found that the deterrent effect 
may not be as widespread as it is sometimes assumed. Audited organizations find audits and recommendations useful, but insist that they have their limits. This mixed picture further complicates the question of where the OAG should dedicate its resources in order to maximize its value. One area that Morin highlights, which is corroborated by the findings presented in Chapter Five, is the importance of parliamentarians to the OAG and other government auditors.

\section{The Importance of Parliament}

The OAG's relationship with Parliament bears scrutiny, for it is undeniably important. The effect of minority and majority governments and the OAG's reliance on Parliament for publicity and recommendation implementation bring nuance to the interactions between these institutions. Although a number of scholars have criticized - and at times, perhaps rightly - the OAG as the tail that wags the Parliamentary dog, ultimately the OAG must answer to Parliament and its political masters. Its independence is necessary, but it lacks the power to force government to take action. Political will is necessary. As one respondent connected to the PAC observed, an appearance before the committee is not necessarily fun:

if you rubbed Parliament the wrong way, a Deputy Minister could find his or her appearance at the Public Accounts a very uncomfortable situation. I didn't set out to make it an uncomfortable situation for them, but I certainly was not interested in making it a little comfortable fireside chat (Interview February 25, 2014).

Deputy Ministers likely do not want to be made to look the fool, especially regarding recommendations to which they have previously agreed. Parliamentarians and the OAG must recognize that recommendation implementation can take time. Yet to ignore the motivational power of an appearance before the PAC is to greatly underestimate the public microscope that MPs can bring upon the government. The sponsorship scandal and HRDC's 'billion dollar 
boondoggle' are proof of that. Audits can be dry and boring. Without the arena of Parliament and its political pressure, implementation of the OAG's recommendations would likely suffer.

If the tenets of responsible government and accountability are to remain important in Canadian politics, Parliament must continue holding government to account. To do so requires information about government's activities. To be sure, accountability is related to a number of areas in the political realm: promises made and kept, differences in ideology, sound public management, and so forth. The OAG does not have a role to play in all of these areas, nor should it. Where its expertise is required is in closing the financial cycle, and providing assurance to parliamentarians that public funds were spent as intended. While controversial to an extent, the OAG's role is also to assess the economy and efficiency of government programs, as well as departmental systems for measuring their effectiveness. Parliamentarians simply cannot obtain such technical and in-depth analysis on their own - not even the PAC. They do not have the time or resources necessary to do so.

Over the last two decades, the OAG has provided a solid and consistent supplementary role to Parliament in these regards. In some ways the process has improved, as the PAC, departments, and OAG have worked together to promote the use and monitoring of action plans. In others, the OAG's work has uncovered high-profile mistakes and scandals, which have driven the Parliamentary agenda and imparted a degree of fame (or infamy, depending on one's perspective) to the institution. In each case, the OAG's credibility and independence have been of the utmost importance to its success and attainment of the public's trust. In spite of its public profile, however, the OAG as watchdog answers to its master. It has a statutorily defined role, of which it is well aware. 
Although the interactions and relationship between Parliament and the OAG have fluctuated over the years, recently there have been no dramatic, sustained or persistent declines in these areas. While Parliamentary review of the OAG's work may flag from time to time, eventually it will experience an uptick when a new government enters its honeymoon phase with the OAG. The data collected points to a correlation between minority governments and increased interaction with the OAG; this is an area that would merit further investigation in the future. The lack of long term trends - other than relative stability - appear to lend credence to the OAG's staying power, as well as government and Parliamentary interest in its work.

If Parliament, the OAG, or the public want to improve the OAG's performance and recommendation implementation rates, a joint effort must be taken between the OAG, Parliament, and government. Communication between departments and the OAG could possibly improve; recommendation formulation could involve a broad array of stakeholders, who in turn would help to monitor the implementation process. Such change has occurred to some extent through endogenous efforts of the $\mathrm{OAG}$ and departments. If more widespread alterations were desired, political will would likely be required; Parliament would have to lead the way.

\section{Institutional Strengths and Limits}

The lack of change in the OAG's performance over the past two decades likely stems, in part, from its institutional character. While it was not always so, in recent years the OAG's institutional nature has provided it with structure and staying power; it has also, however, limited the OAG in important ways.

Interviews with current and former officials from the OAG almost all reflected an acute awareness of the organization's statutory limitations and obligations. While there were slight 
differences of opinion regarding the OAG's main duties, each and every response came back to auditing. This is unsurprising. Yet an awareness of the limitations of auditing was also present: top officials knew that they could not go in and perform any type of audit or 'management study.' Instead, the stipulations laid out in the Auditor General Act were almost always referred to. The impression given from these discussions was one of the OAG as very much a self-aware institution. Its role and history, in conjunction with its credibility and independence, have resulted in an institution whose employees - at least in senior management - are keenly aware of where they fit in, where to push, and where to acquiesce.

The limitations these institutional strictures place on the OAG's work reflect, to a large extent, the traditional structure-agency debate in the social sciences. The nuances of that debate cannot be explored here, but it is clear that the structures of the OAG shape the actions - thereby influencing the agency - of the actors within the institution. Gone, for the most part, are the days when John Lorn McDougall, Watson Sellar, Maxwell Henderson, or James Macdonnell could pursue activities outside of the OAG's unclear mandate. The impact of the debates of the 1960s and 1970s continues to be felt; the Auditor General Act has succeeded in clarifying the role and actions of the OAG, probably more than Pierre Trudeau imagined it would. As a result, auditors general of the past two decades appear to have lost a degree of the agency their predecessors had.

While some will still say the actions of the OAG are too broad and disproportionate to what an auditor should do, for the most part the auditing process itself has been clarified as well. A legitimate debate can be had over the scope of the OAG's audit work, but its continual refinement of audit methodologies - for both financial and performance audits - has no doubt contributed to increased validity and rigour in the auditing process. If the research conducted for this project is any indication, the OAG will likely continue to adopt new best practices as they 
evolve, and endogenous change will continue to play a minor role in the Office. Yet change is not inimical to a political institution such as the OAG. Indeed, it must happen; institutions that remain absolutely static cannot always respond to new challenges and opportunities.

\section{The More Things Change, the More They Stay the Same}

Trying to determine how something changes is sometimes easy, and sometimes difficult. When dealing with a political institution that has a history spanning across three centuries, an intricate relationship with Canada's political structure, hundreds of employees, and a distinct public profile, offering a definitive assessment of changes in its performance is a tall order. And yet, according to the metrics identified, the absence of dramatic change in recent years is evident. The OAG's performance in carrying out its accountability function has remained steady over the past two decades. Its relationship with Parliament, while experiencing a degree of nuance and fluctuation, has likewise been one of consistency.

This stability has not emerged from a vacuum. The OAG's historical roots, the actions of individual auditors general, and significant controversies over its role have all contributed to the current incarnation of this political institution. Throughout these changes and disputes, the OAG has never wavered from its initial mandate: auditing the accounts of the government and providing that information to parliamentarians. Due to its independence and credibility, in the process the OAG has come to be known as the financial watchdog, guarding the public's money and alerting Parliament to any potential issues. The watchdog will continue to guard the premises, providing Parliament with information it may not otherwise easily procure.

A number of areas touched on in this thesis deserve greater research and exploration. Perhaps of most interest is the relationship between the OAG and Parliament, and the effect 
thereon of minority and majority governments. In turn, it must be asked how these variables may affect the accountability processes of Parliament. To be sure, at times a sense emerged that the government and the OAG are 'playing a game.' The government would agree to recommendations, in an attempt to diminish the watchdog's bite. The OAG, well aware of its political power, would push in some areas, and tread carefully in others. The interaction between the two is sophisticated. When the minority-majority and opposition-power dichotomies are considered, the game only grows more interesting. At this point, little more can be said of this phenomenon. More interviews, and perhaps more quantitative analysis, are needed to better understand these interactions.

Canadians, the government, and the OAG can take heart in the reliable operation of this important institution. It will likely never be free of controversy, but in politics, few things are. Over the course of time the OAG has been strengthened, but it remains cognizant of its place and role in the accountability process. As Franks noted in his famous tome The Parliament of Canada, "there was no golden age of accountability...the golden age is the present" $(1987,256)$. Regarding the OAG, at least, those words have likely never been truer than they are today. The OAG has trod a tumultuous path to arrive at its current position. Canadians are now reaping the fruits of that labour. Although the OAG has had to change over time, it now appears to have entered a phase where it can afford to stay the same. 


\section{Appendix A: Office of the Auditor General Interview Questionnaire}

\section{Section 1: General Questions}

1. In your opinion, what are the three most important duties of the OAG?

2. How would you explain the difference between a performance audit, a comprehensive audit, and a value for money audit?

\section{Section 2: OAG Performance Over Time}

1. What would you identify as the most significant changes to OAG methods, criteria, and standards over the last two decades?

2. Has the OAG's approach to measuring 'effectiveness' changed in your experience?

3. The 2002 Status Report described itself as a new way to follow up on recommendations, in an attempt to rely less on departmental self-reporting of implementation rates.

a. How was recommendation follow-up performed before this status report? Were official follow-up audits performed prior to 2002 ?

b. What spurred the OAG to stop relying on departmental self-reporting of recommendation implementation?

c. Who should be responsible for monitoring and reporting on recommendation implementation?

4. Why does the OAG only conduct follow up audits on a minority of its recommendations?

a. What is the procedure for selecting past recommendations to re-audit for status reports?

b. Should the OAG be following up on a greater percentage of its recommendations?

c. Has the proportion or rate of follow-up audits varied over time?

5. To what extent do different auditors general affect the overall operation and priorities of the OAG?

6. Do you think the majority of OAG recommendations are fully or satisfactorily implemented?

a. In your view, has there been an increase or decrease in implementation over time? 
b. Have some recommendations or implementations had a greater impact or profile than others?

7. Does the OAG generally complement departmental audit and evaluation functions, or do significant gaps or excessive overlap exist?

\section{Section 3: The OAG's Relation to Parliament and Government}

1. In your view, have executive branch reactions to $\mathrm{OAG}$ recommendations changed over time?

a. If so, have electoral changes in government led to different reactions to the OAG and its recommendations?

b. Has there been a change over time in bureaucratic or departmental reactions to the $\mathrm{OAG}$ and its recommendations?

2. How would you characterize the OAG's interactions with the Public Accounts Committee (PAC) and its members?

a. Has interaction between the OAG and the PAC, or with other parliamentarians, increased or decreased over time?

\section{Closing Question}

1. Is there anything else you'd like to add? 


\section{Appendix B: Standing Committee on Public Accounts Interview Questionnaire}

\section{Section 1: General Questions}

1. In your opinion, what are the three most important duties of the PAC?

a. In your opinion, what are the three most important duties of the OAG?

2. Would you say the OAG is a 'financial watchdog'?

a. Would you say the PAC is a 'financial watchdog'?

\section{Section 2: Relation to OAG}

1. How would you characterize the PAC's relationship with the OAG?

2. In your experience, did changes to the PAC's membership over time result in changes to the way the PAC interacted with the OAG?

3. In your experience, did the OAG's performance in carrying out its role change over time?

4. In your view, how important is it that OAG recommendations be implemented?

5. During your tenure, how often did the PAC review departmental action plans and progress reports related to OAG or PAC recommendations?

\section{Section 3: Performance Over Time}

1. Did the operation of the PAC change over the course of your involvement on the committee?

2. In its most recent performance report, the $\mathrm{OAG}$ points to a decline in parliamentary committee review of OAG audits.

a. Why might this be happening?

b. Is this trend a potential problem?

c. How important is it that the OAG and Parliament have regular or frequent interactions? 


\section{Section 4: Relation to Parliament and Government}

1. In your view, have executive branch reactions to $\mathrm{OAG}$ or PAC recommendations changed over time?

a. If so, have electoral changes in government led to different reactions to the OAG or PAC and their recommendations?

\section{Closing Question}

1. Is there anything else you'd like to add? 


\section{Appendix C: Internal Audit Questionnaire}

1. What role does internal audit and evaluation play in a department?

a. What are the three most important duties of internal audit and evaluation?

2. What methods or types of audit do you perform?

a. Do audits or evaluations play a more prominent role in your work?

3. What type of audit constitutes the bulk of your work?

4. How many audits do you perform in a year?

5. Does internal audit only perform 'after the fact' auditing, or is there any pre-spending analysis?

6. How does internal audit relate to other parts of a department?

7. Is there any external oversight, cooperation, integration, or verification of a department's Audit and Eval?

8. Do you follow-up on your recommendations?

9. Would you see internal audit as being a type of 'financial watchdog'?

10. Does the OAG generally complement departmental audit and evaluation functions, or do significant gaps or excessive overlap exist?

\section{Closing Question}

2. Is there anything else you'd like to add? 


\section{$\underline{\text { References }}$}

Aucoin, Peter. 1998. Auditing for Accountability: The Role of the Auditor General. Ottawa: The Institute on Governance.

Aucoin, Peter, Mark D. Jarvis and Lori Turnbull. 2011. Democratizing the Constitution. Toronto: Edmond Montgomery Publications.

Balls, Herbert R. 1978. "The Watchdog of Parliament: the Centenary of the Legislative Audit" Canadian Public Administration. 21(4): 584-617.

Behn, Robert D. 2001. Rethinking Democratic Accountability. Washington: Brookings Institution Press.

Bell, Jeffrey Graham. 2006. “Agents of Parliament: A New Branch of Government?” Canadian Parliamentary Review. 29(1): 13-21.

Bemelmans-Videc, Marie-Louise, Jeremy Lonsdale, and Burt Perrin. 2007.

Making Accountability Work: Dilemmas for Evaluation and for Audit. New Jersey: Transaction Publishers.

Brodtrick, Otto. 2004. "How does an auditor general's office see itself?" Canadian Public Administration 47 (2): 225-242.

Canada. Auditor General Act. R.S.C., 1985, c. A-17

Canada. House of Commons. Standing Orders of the House of Commons. Ottawa: Public Works and Government Services Canada. Available at http://www.parl.gc.ca/About/House/StandingOrders/SOPDF.pdf (Last Accessed June 22, 2014).

Canada. Office of the Auditor General. 1997. Performance Report for the period ending 31 March 1997. Available at http://www.oag-bvg.gc.ca/internet/English/acc rpt e 18752.html (Last Accessed 4 May 2014)

Canada. Office of the Auditor General. 1998. Performance Report for the period ending 31 March 1998. Available at http://www.oag-bvg.gc.ca/internet/English/acc_rpt_e_18327.html (Last Accessed 4 May 2014)

Canada. Office of the Auditor General. 1999. Performance Report for the period ending 31 March 1999. Ottawa: Public Works and Government Services Canada.

Canada. Office of the Auditor General. 2000. Performance Report for the period ending 31 March 2000. Ottawa: Public Works and Government Services Canada.

Canada. Office of the Auditor General. 2001. Performance Report for the period ending 31 March 2001. Ottawa: Public Works and Government Services Canada. 
Canada. Office of the Auditor General. 2002. Performance Report for the period ending 31 March 2002. Ottawa: Public Works and Government Services Canada.

Canada. Office of the Auditor General. 2003. Performance Report for the period ending 31 March 2003. Available at http://www.collectionscanada.gc.ca/webarchives/20060120095625/http://www.tbssct.gc.ca/rma/dpr/02-03/oag-bvg/oag-bvg03d-pr e.asp?printable=true (Last Accessed 4 May 2014)

Canada. Office of the Auditor General. 2004. Performance Report for the period ending 31 March 2004. Available at http://www.collectionscanada.gc.ca/webarchives/20060120080438/http://www.tbssct.gc.ca/rma/dpr/03-04/oag-bvg/oag-bvgd34-pr_e.asp?printable=true (Last Accessed 4 May 2014)

Canada. Office of the Auditor General. 2005. 2004-05 Estimates: Performance Report. Ottawa: Public Works and Government Services Canada.

Canada. Office of the Auditor General. 2006. 2005-06 Estimates: Performance Report. Ottawa: Public Works and Government Services Canada.

Canada. Office of the Auditor General. 2007. 2006-07 Estimates: Performance Report. Ottawa: Public Works and Government Services Canada.

Canada. Office of the Auditor General. 2008. 2007-08 Estimates: Performance Report. Ottawa: Public Works and Government Services Canada.

Canada. Office of the Auditor General. 2009. 2008-09 Estimates: Performance Report. Ottawa: Public Works and Government Services Canada.

Canada. Office of the Auditor General. 2010. 2009-10 Estimates: Performance Report. Ottawa: Public Works and Government Services Canada.

Canada. Office of the Auditor General. 2011 2010-11 Estimates: Performance Report. Ottawa: Public Works and Government Services Canada.

Canada. Office of the Auditor General. 2012. 2011-12 Estimates: Performance Report. Ottawa: Public Works and Government Services Canada.

Canada. Office of the Auditor General. 2013. 2012-13 Estimates: Performance Report. Ottawa: Public Works and Government Services Canada.

Canada. Office of the Auditor General. 2002. A Status Report of the Auditor General of Canada to the House of Commons. Ottawa: Public Works and Government Services Canada. 
Canada. Office of the Auditor General. 2003. A Status Report of the Auditor General of Canada to the House of Commons. Ottawa: Public Works and Government Services Canada.

Canada. Office of the Auditor General. 2005. A Status Report of the Auditor General of Canada to the House of Commons. Ottawa: Public Works and Government Services Canada.

Canada. Office of the Auditor General. 2006. A Status Report of the Auditor General of Canada to the House of Commons. Ottawa: Public Works and Government Services Canada.

Canada. Office of the Auditor General. 2007 A Status Report of the Auditor General of Canada to the House of Commons. Ottawa: Public Works and Government Services Canada.

Canada. Office of the Auditor General. 2009. Status Report of the Auditor General of Canada to the House of Commons. Ottawa: Public Works and Government Services Canada.

Canada. Office of the Auditor General. 2011. Status Report of the Auditor General of Canada to the House of Commons. Ottawa: Public Works and Government Services Canada.

Canada. Office of the Auditor General. 2013. Spring 2013 Report of the Auditor General of Canada. Ottawa: Public Works and Government Services Canada.

Canada. Report of the Independent Review Committee on the Office of the Auditor General of Canada. Ottawa: 1975.

Canada. Royal Commission on Financial Management and Accountability. Ottawa: 1979.

Defoy, Sebastien T. 2011. "Performance Auditing at the Office of the Auditor General of Canada: Beyond Bean Counting" Library of Parliament Publication No. 2011-71-E. Available at http://www.parl.gc.ca/Content/LOP/ResearchPublications/2011-71-e.pdf (Last Accessed 11 April 2013).

Dye, Kenneth M. 1984. Controlling the Public Purse: Is Parliament's Sovereignty Threatened? Ottawa: Carleton University.

Dye, Kenneth. 2003. "Another Former Auditor General Discusses the Role and History of this Important Office.” In Guardians on Trial, ed. Anthony Hall. Toronto: Dundurn Press, 232-245.

Franks, C.E.S. 1987. The Parliament of Canada. Toronto: University of Toronto Press.

Gauthier, Jean-Robert. 1993. "Accountability, Committees and Parliament.” In Canadian Parliamentary Review 16(2): 7-9.

Good, David A. 2007. The Politics of Public Money. Toronto: University of Toronto Press.

Harty, Siobhan. 2005. “Theorizing Institutional Change” In New Institutionalism: Theory and Analysis, ed. Andre Lecours. Toronto: University of Toronto Press, 51 - 79. 
Henderson, Maxwell. 1984. Plain Talk! Toronto: McClelland and Stewart Limited.

House of Commons Procedure and Practice. 2009. Available at http://www.parl.gc.ca/procedurebook-livre/Document.aspx?Language $=\mathrm{E} \& M o d e=1 \&$ sbdid=F26EB116-B0B6-490C-B41033D985BC9B6B\&sbpid=92E352ED-BE17-44E8-82FE-5F47834435FC Last accessed June 5, 2014.

Leclerc, Guy, W. David Moynagh, Jean-Pierre Boisclair, and Hugh R. Hanson. 1996. Accountability, Performance, Reporting, Comprehensive Audit - An Integrated Perspective. Ottawa: CCAF-FCVI Inc.

Lonsdale, Jeremy. 2011. "Introduction" In Performance Auditing: Contributing to Accountability in Democratic Government, eds. Jeremy Lonsdale, Peter Wilkins, and Tom Ling. Cheltenham: Edward Elgar Publishing Limited.

Malloy, Jonathan. 2004. "An auditor's best friend? Standing committees on public accounts." Canadian Public Administration 47 (2): 165-183.

March, James G. and Johan P. Olsen. 2006. "Elaborating the "New Institutionalism"." In The Oxford Handbook of Political Institutions, eds. R. A. W. Rhodes, Sarah A. Binder, and Bert A. Rockman. Oxford: Oxford University Press, 3-20.

Morin, Danielle. 2004. "Measuring the impact of value-for-money audits: a model for surveying audited managers." Canadian Public Administration 47 (2): 141-164.

Mulgan, Richard. 2003. Holding Power to Account: Accountability in Modern Democracies. Basingstoke: Palgrave MacMillan.

Power, Michael. 1997. The Audit Society: Rituals of Verification. New York: Oxford University Press.

Roberts, Alasdair. 1996. "Worrying about misconduct: the control lobby and the PS 2000 reforms." Canadian Public Administration 39 (4): 489-523.

Saint-Martin, Denis. 2004. "Managerialist advocate or "control freak"? The Janus-faced Office of the Auditor General" Canadian Public Administration. 47 (2): 121-40.

Savoie, Donald J. 1990. The Politics of Public Spending in Canada. Toronto: University of Toronto Press.

Simmons, Julie M. and Amy Nugent. 2013. "Panacea or Peril? Intergovernmental Accountability and the Auditor General." In Overpromising and Underperforming? Understanding Accountability and Evaluating Intergovernmental Accountability Regimes, eds. Peter Graefe, Julie M Simmons, and Linda A. White. Toronto: University of Toronto Press, 284- 303.

Sinclair, Sonja. 1979. Cordial But Not Cosy: A History of the Auditor General. Toronto: McClelland and Stewart Limited. 
Stilborn, Jack. A. 2010. "The Officers of Parliament: More Watchdogs, More Teeth, Better Governance?" In How Ottawa Spends 2010-2011, eds. G. Bruce Doern and Christopher Stoney. Montreal: McGill-Queen's University Press, 243-260.

Sutherland, S.L. 2002. "The Office of the Auditor General of Canada: Government in Exile?" Queen's University School of Policy Studies: Working Paper 31.

Sutherland, S.L. 1980. "On the Audit Trail of the Auditor General: Parliament's Servant, 19731980" Canadian Public Administration. 23(4): 616-644.

Ward, Norman. 1951. The Public Purse. Toronto: University of Toronto Press.

Wildavsky, Aaron. 1964. The Politics of the Budgetary Process. Boston: Little, Brown and Company. 